\title{
Novel PVA nanocomposite films: Synthesis, structure, optical and photocatalytic properties evaluation.
}

yamanappagouda amaregouda ( $\sim$ ygbalaganur@gmail.com )

Rani Channamma University

Kantharaju Kamanna

\section{Research Article}

Keywords: Polyvinyl alcohol, nanocomposite films, Aspartic acid, adsorption, photocatalysis, optical property

Posted Date: April 21st, 2021

DOI: https://doi.org/10.21203/rs.3.rs-437044/v1

License: (1) This work is licensed under a Creative Commons Attribution 4.0 International License. Read Full License 


\title{
Novel PVA nanocomposite films: Synthesis, structure, optical and photocatalytic properties evaluation. Yamanappagouda Amaregouda and Kantharaju Kamanna* School of Basic Sciences: Department of Chemistry, Rani Channamma University, Vidyasangama, $P-B, N H-4$, Belagavi -591156, Karnataka. Tel: +91(0831)-2565203; Fax: +91-(0831)-2565240 \\ *Corresponding author: E-mail: kk@rcub.ac.in
}

\begin{abstract}
The present work describes design and preparation of novel PVA nanocomposite films using $\mathrm{CuO}$ NTs and Asp by solution casting method. The required CuO NTs prepared by novel biogenic method using Robinia Pseudoacacia Leaf Extract. The prepared CuO NTs and nanocomposite films are characterized by various spectroscopy techniques. The adsorption and photocatalytic efficiencies of PVA nanocomposite films were compared with pristine $\mathrm{CuO}$ NTs. The adsorption capacity of PVA nanocomposite films showed higher due to functional groups, presence of active sites, high surface activity and semiconducting nature of $\mathrm{CuO}$ NTs and Asp embedded in PVA matrix. The adsorption behavior of the nanocomposite shows that adsorption isotherms and kinetics are in good agreement with Langmuir equation, Freundlich equation and pseudo-secondorder, respectively. The comparative photocatalytic activities of the $\mathrm{CuO}$ NTs other nanocomposite films are examined methylene blue (MB) as a substrate degradation, and film $\mathrm{PVA} / \mathrm{CuO} \mathrm{NTs} / \mathrm{Asp}$ showed highest (up to 77\%) degradation compared to other films and $\mathrm{CuO}$ NTs in 50 min time duration. The improved photocatalytic behavior of PVA nanocomposite film attributed to its narrower band gap reduces the recombination rate of exited electron-hole, enhanced UV-Vis absorption intensity, improved utilization of sunlight and enhanced adsorption of dye due to functional groups, surface wettability, hydrophilic surface and self-cleaning nature. Keywords: Polyvinyl alcohol, nanocomposite films, Aspartic acid, adsorption, photocatalysis, optical property.
\end{abstract}

\section{Introduction}

As industry and the economy have advanced, environmental pollution is also increased, it is directly threatening to human health and the environment [1]. Water pollution has to be one of the most serious environmental problems on the planet [2]. There is a significant increased wastewater containing dye disposed into natural water supplies, mainly produced in the textile industry [3]. 
Among the dyes used in textile, methylene blue (MB) is the most commonly used dye for cotton, wood, and silk; it is a cationic dye that can cause breathing problems, as well as permanent eye damage, burning sensations, nausea, excessive sweating, mental confusion, and methemoglobinemia if inhaled directly [4]. Hence, the expulsion of this organic dyes from the wastewater is of the great significance to environmental safety [5]. Photocatalysis is the promising method for conversion organic dyes into not-toxic simple molecules such as $\mathrm{CO}_{2}$ and $\mathrm{H}_{2} \mathrm{O}[6,7]$. However, there are a number of drawbacks of using powder photocatalysts in wastewater treatment.; difficult separation of the catalyst from the suspension, higher catalyst loading on the suspension aggregation of its particles [8,9]. Hence, heterogeneous semiconductor photocatalyst nanocomposites have great potential for converting solar energy into chemical energy and for decomposing organic dyes [10,11]. The present work reported, PVA/CuO NTs/Asp nanocomposites are better materials for the pollutant $\mathrm{MB}$ dye removal because of its high; photocatalytic activity [12], optical transparency [13], refractive index [14], optical absorption [15], photovoltaic performance of low-bandgap [16,17], adsorption [18], hydrophilic surface [19] and self-cleaning [20,21]

Polyvinyl alcohol (PVA) is hydrophilic synthetic polymer which has now received a lot of attention from researchers due to its excellent film-forming properties, nontoxicity, biodegradability and optical transparency [22,23]. Adsorption of Dyes Using Poly (vinyl alcohol) (PVA) and PVA-Based Polymer Composite adsorbents are well studied in the literature [24]. PVA has been widely investigated as a host matrix for various types of dopants such as nanofillers and bioorganic molecules to modulate the effective photocatalytic properties $[25,26]$. PVA along with semiconducting material composite films are demonstrated efficient dye degradation [27,28]. Researchers reported that some of the nanofiller doped PVA composites, and biopolymer blend PVA showed efficient removal of MB dye [29-32]. researchers also have reported that nanofiller and biomolecule doped PVA composites show excellent optical properties [33,34].

Low dimensional $\mathrm{CuO}$ nanomaterials, particularly 1D $\mathrm{CuO}$ nanomaterials have received great attention because of their huge surface area, narrow bandgap with p-type semiconductor, high refractive index, enhanced optical property, ability to spread uniformly in polymers and potential application in converting solar energy through photocatalysis for the degradation of organic pollutants in water [35-37]. In particular $\mathrm{CuO} \mathrm{NTs} \mathrm{belong} \mathrm{to} \mathrm{one} \mathrm{dimensional} \mathrm{nanomaterial,} \mathrm{it} \mathrm{also}$ act as a electrode performed as both a P-type semiconductor for generating the cathodic photo 
current signal and a biomimetic catalyst to synergize the biological catalyst XOD to constitute the dual catalysis system [38]. In another paper reported $\mathrm{CuO}$ NTs, having better bonding strength and, hence, a longer lifetime [39]. Researcher investigated many applications of CuO NTs and its doped films used for photocatalysis, optoelectronic properties [40-43]. The strong hydrogen bonding between $\mathrm{CuO}$ and PVA reported [44]. The physical properties and application of $\mathrm{CuO}$ NPs with PVA composite films for optical properties is well documented [45].

Amino acid is a fundamental component of protein and has a series of potential attributes for effective dye removal [46-49], due to the following properties such as presence of amine $\left(-\mathrm{NH}_{2}\right)$ and carboxyl $(-\mathrm{COOH})$ functional groups [50,51], surface adsorption [52,53], complexation (coordination) [54,55], ion exchange [56], pI value [57], hydrophobicity, hydrophilicity [58,59] and exhibits dielectric and high refractive index [60,61]. Among the twenty amino acids Asp is unique properties, due to the presence of side chain containing additional carboxyl group resulted negative charge. Researcher demonstrated the strong formation of complex between CuO NPs and Asp is documented [62]. Literature reported semiconducting properties of Asp is alone $5.02 \mathrm{eV}$ and also exhibit very good hydrophilic property which helps potential removal dye is established [63-65].

To reach our purpose, we first synthesized CuO NTs by using biogenic method, which is then loaded onto PVA polymer to obtain film F2 (PVA/CuO NTs) and F3 (PVA/CuO NTs/Asp) nanocomposite using solution casting technique. The effect of structural, morphological and optical properties of the prepared films is investigated. Moreover, the adsorption and photocatalytic activities of the prepared transparent nanocomposite films have been evaluated for the degradation of methylene blue (MB) dye because of its stability under visible light irradiation. The Use of Asp allows the CuO NTs to form complex layer on the surface of PVA film, which can enhance both the crystallinity and optical properties of the prepared nanocomposite, and also grow-up pore volume and diameter. Thus, the adsorption process enhanced by PVA/CuO NTs/Asp nanocomposite, which showed high performance of the photocatalytic degradation of the MB dye in a short time at visible light. Further, the MB dye degradation was confirmed by LC-MS analysis. The optical properties of nanofiller doped PVA composite film (absorption, transmittance, direct bandgap, indirect bandgap, extinction coefficient, refractive index) are the evidence for the effective photocatalytic activity, further the complex formation between CuO NTs and Asp in the 
film F3 is confirmed by the FT-IR spectra, UV-Vis absorption intensity and the blue color appearance of the prepared film.

\section{Materials and Methods}

\section{Materials}

Polyvinyl alcohol (Av. Mol. Wt. 60,000 to 1,25,000) (HIMEDIA) completely hydrolyzed, copper nitrate and Aspartic acid (Sigma-Aldrich, India) were utilized as received. Robinia pseudoacacia Leaves (RPL) were collected from the nearby rural area Balaganur (Sindhanur), Karnataka, India. Double distilled water used throughout the work. The preparation of the PVA and blend nanocomposite films is prepared using casting method. Water contact angle properties of the prepared films were measured by contact angle instrument by sessile drop method employing a contact angle meter model DMs-401 (Kyowa Interface Science Co. Ltd., Tokyo). The biogenic nanoparticle preparation was monitored, and optical properties measured (for prepared films) using UV-Vis-1800 Shimadzu spectrophotometer with wavelength range of 200-800nm. ATR-FTIR analysis employed to determine prominent chemical bonding and interaction between the films. FT-IR spectra of prepared nanocomposite films were recorded in ATR mode (Thermo scientific) between the wavelength $400-4000 \mathrm{~cm}^{-1}$ at room temperature. The morphology of the CuO NTs and films prepared were obtained using VEGA3, TESCAN (CZECH REPUBLIC) equipment followed by EDX data of $\mathrm{CuO}$ NTs by BRUKER nano, GmbH, D-12489 (Germany) with accelerating voltage ranging from 0 to $30 \mathrm{kV}$. The powder X-ray diffraction (XRD) analysis was carried out using a Rigaku miniflex, the reflection mode with $\mathrm{Cu} \mathrm{K} \alpha$ radiation at $30 \mathrm{kV}, 10 \mathrm{~mA}$ a scan rate of $2 \% / \mathrm{min}$ and a scan range of $10^{\circ}$ to $90^{\circ}(2 \theta)$. The ultrasonic cleaner of power $33 \mathrm{kHz}$, make Leela Sonic used.

\subsection{Preparation of Robinia Pseudoacacia Leaf Extract}

Freshly Robinia Pseudoacacia Leaves are collected from the local and washed with tap water to expel dust and other particles. The washed leaves are dried in shade for four days, and powdered using electric processor. The leaf extraction carried out, briefly $40 \mathrm{~g}$ of powder soaked in $100 \mathrm{~mL}$ deionized water and boiled for 50 min until the color of the watery solution to light yellow. The mixture was filtered using Whatman filter paper to get aqueous leaf extract and solution was stored at $4{ }^{\circ} \mathrm{C}$ until further use [66].

Preparation of $\mathrm{CuO}$ NTs 
The above RPL leaf extract $(100 \mathrm{~mL})$ was taken and boiled to $60-80{ }^{\circ} \mathrm{C}$ with stirring, to this added copper nitrate trihydrate in $100 \mathrm{~mL}$ double distilled water under vigorous stirring until black precipitate separated out from the solution. After the formation of black precipitate, stirring was stopped and left for the settle, and filtered, repeatedly washed with double distilled water and ethanol for several times till the $\mathrm{pH}$ reached neutral. Subsequently material was dried at $80{ }^{\circ} \mathrm{C}$ for $16 \mathrm{~h}$ at oven followed by calcination at $500{ }^{\circ} \mathrm{C}$ for $4 \mathrm{~h}$ [67].

\section{Preparation of PVA films}

The PVA/CuO NTs/Asp (F3) composite film was prepared by solution casting method by reported procedure [68], briefly $2.00 \mathrm{~g}, 0.01 \mathrm{~g}, 0.02 \mathrm{~g}$ respectively taken ingredients in $100 \mathrm{~mL}$ distilled water. The solution was prepared by dissolving PVA in $100 \mathrm{~mL}$ double distilled water mixing vigorously about $60 \mathrm{~min}$ at $70^{\circ} \mathrm{C}$. The $\mathrm{CuO}$ NTs dispersed in sonication was added to the PVA solution, next Aspartic acid dissolved in water, was added (after addition blue color appeared due to the formation of $\mathrm{CuO}$ NTs with Asp complex) to the PVA solution. After adding all the composition, the transparent solution homogenized by applying vacuum to remove bubbles, and casted using petri dish, dried over $30^{\circ} \mathrm{C}$. The other films PVA/CuO NTs (F2) and PVA (F1) are also prepared by the above method with respective additive/s and final films picture shown in the Figure 1.

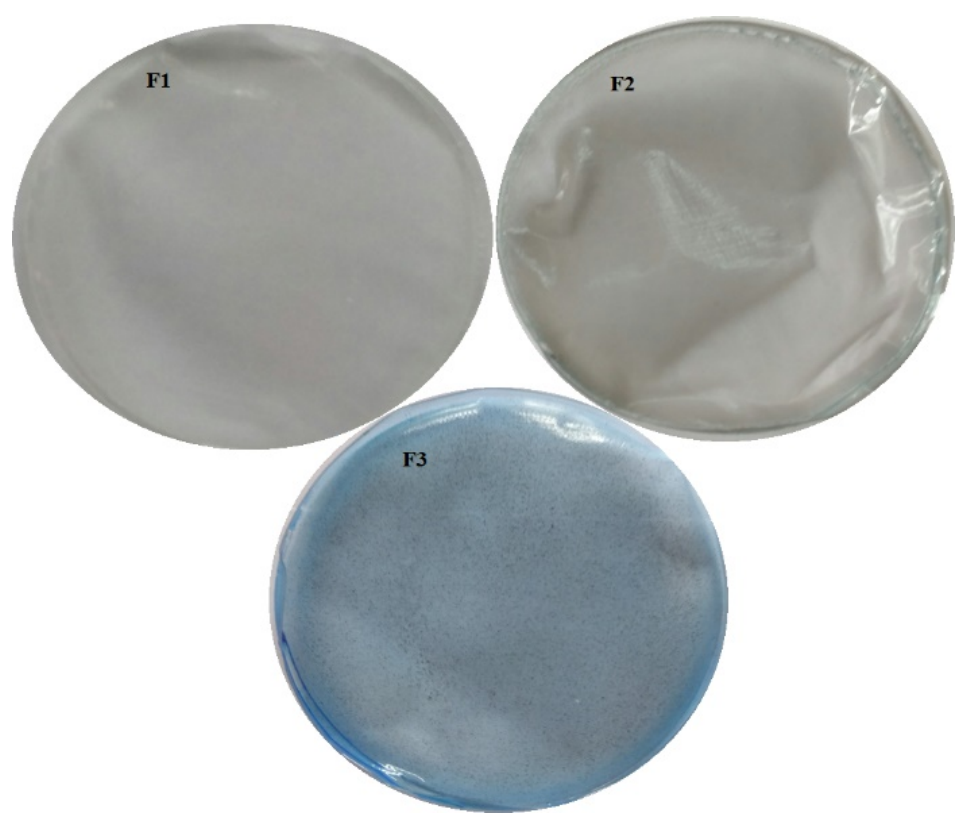

Fig. 1 Image of prepared PVA and its composite films 


\section{Characterization}

The absorption spectra of CuO NTs, copper nitrate and plant extract are measured by UV-Vis spectroscopy. Fourier-transform infrared spectroscopy (FT-IR) was taken for CuO NTs, F1, F2, F3 and F4 composite films. The surface morphology and EDX of the CuO NTs were observed by scanning electron microscopy. The X-ray diffraction (XRD) of the $\mathrm{CuO} \mathrm{NTs}, \mathrm{F} 1, \mathrm{~F} 2$ and F3 composite films performed using an X-ray diffractometer.

\section{Thickness of the films}

The physical thickness of the prepared films is an important tool for the determination of optical properties and was measured using a screw gauge. The thickness was calculated by considering at least three reading of the different position of the film and are averaged.

\section{Water contact angle (WCA)}

Water contact angle of the prepared films were carried out to study surface wettability properties measured using reported procedure [66]. Briefly, the film $(2 \mathrm{~cm} \times 2 \mathrm{~cm})$ placed on a sample holder and double distilled water is dropped on the surface of the film, followed by the immediate capture of the image. Each contact angle value is the average of four different position of the same film.

\section{Optical properties evaluation}

The optoelectronic properties of the prepared films were examined in UV-Vis-1800 Shimadzu spectrophotometer wavelength range 200-800 $\mathrm{nm}$. The optical absorption, direct and indirect optical band gap, extinction coefficient and refractive index properties are studied for the prepared films using reported procedure method [45].

\section{Photodegradation assessment, setup and sorption}

Photocatalytic properties of the prepared films were determined on MB dye as a model example. The films F1, F2, F3 and F4 with a size of 2 x $2 \mathrm{~cm}$ was dipped into $50 \mathrm{~mL}$ of MB aqueous solution $(10 \mathrm{mg} / \mathrm{L})$ taken in $250 \mathrm{~mL}$ beaker, simultaneously the $\mathrm{pH}$ value would be monitored. The solution of MB dye and CuO NTs, Pure PVA and PVA composite photocatalyst was subjected to vigorous stirring in a reactor under darkness for $15 \mathrm{~min}$ to attain the equilibrium and then transferred to the photocatalytic reactor. The MB dye degradation experiments were carried out in the presence of sunlight. During photocatalytic reaction $1 \mathrm{~mL}$ of $\mathrm{MB}$ solution was drawn at initial and different time interval to examine MB concentration in UV-Vis spectrophotometer [69].

The photodegradation rate for each time interval is calculated by using following equation (1). 


$$
\% \text { Photodegradation }=\frac{\left(C_{0}-C_{i}\right) \times 100}{C_{0}}----1
$$

\section{Results and Discussion}

\section{UV-Visible spectroscopy}

The absorption spectra is used to monitor the formation of $\mathrm{CuO}$ NTs and other sample used for the preparation of $\mathrm{CuO}$ NTs. The absorption spectra of the plant extract, copper nitrate and CuO NTs are presented in Figure 2. The absorbance of the NTs depends on the particle size, shape, spacing between the NTs and media used. At room temperature, spectra exhibited $\lambda_{\max }$ absorption peak at $298 \mathrm{~nm}$ for the plant extract contains many phytochemicals, $293 \mathrm{~nm}$ for the copper nitrate and 295 $\mathrm{nm}$ for the $\mathrm{CuO}$ NTs prepared are observed [70].

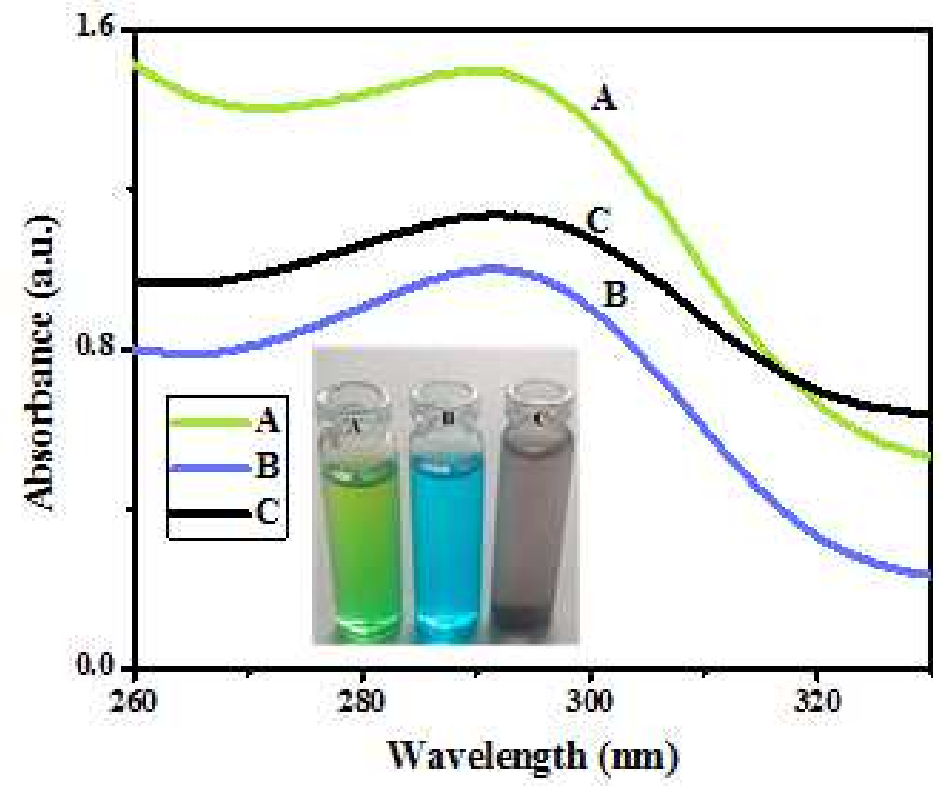

Fig. 2 UV-Vis spectra of: A) plant extract, B) $\mathrm{Cu}\left(\mathrm{NO}_{3}\right)_{2} .3 \mathrm{H}_{2} \mathrm{O}$ and $\left.\mathrm{C}\right) \mathrm{CuO}$ NTs

\section{Structural morphology}

The SEM-EDX image was obtained for the prepared CuO NTs and was appended in Figures 3 and 4. It is observed that, the $\mathrm{CuO}$ NTs prepared have a well-defined morphology and are nanotube shape. The EDX spectrum of the synthesized CuO NTs is presented in Figure 3 it revealed the purity and formation $\mathrm{CuO}$ NTs. Figure 4 shows the surface morphology of the prepared films (confirm the formation of $\mathrm{CuO} \mathrm{NTs}$ and $\mathrm{CuO} \mathrm{NTs/Asp-complex)} \mathrm{observed} \mathrm{nanotube} \mathrm{network}$ 
connection between $\mathrm{CuO}$ NTs and Asp. XRD Measurements is depicted in Figure 5, the XRD patterns of prepared $\mathrm{CuO}$ NTs is similar to the $\mathrm{CuO}$ nanowires reported by Dahai Zhu et al [35]. The average crystallite size of CuO NTs was calculated using Scherrer formula, and was found to be about $10.03 \mathrm{~nm}$ indicating nano crystalline natures. The distinctive peaks located at $2 \theta=32.49^{\circ}$, $35.47^{\circ}, 38.77^{\circ}, 48.74^{\circ}, 53.45^{\circ}, 58.23^{\circ}, 61.12^{\circ}, 66.21^{\circ}$ and $68.10^{\circ}$ are assigned to (110), (002), (111), (-202), (020), (202), (-113), (-311) and (220) plane orientation of CuO (JCPDS 80-1268). It clearly revealed that nanosized $\mathrm{CuO}$ was successfully prepared by biogenic method.

The X-ray diffraction measurement was performed to examine the nature of the crystallinity of the PVA composite polymer films prepared [71]. It is well documented the PVA polymer films exhibited a semi-crystalline structure with peaks at the $2 \theta$ angles of $19.5^{\circ}$. But it was also clearly observed that the peak intensity of the PVA composite films slightly reduced when CuO NTs and Asp fillers were added indicates changes occurs in the F2 and F3 films as compared to F1 film. In the F2 film $2 \theta$ peaks observed at $35^{\circ}$ and $39^{\circ}$ indicates the presence of CuO NTs. And in the F3 film $2 \theta$ peaks observed at $53^{\circ}$ indicates the formation of complex between CuO NTs and Asp.

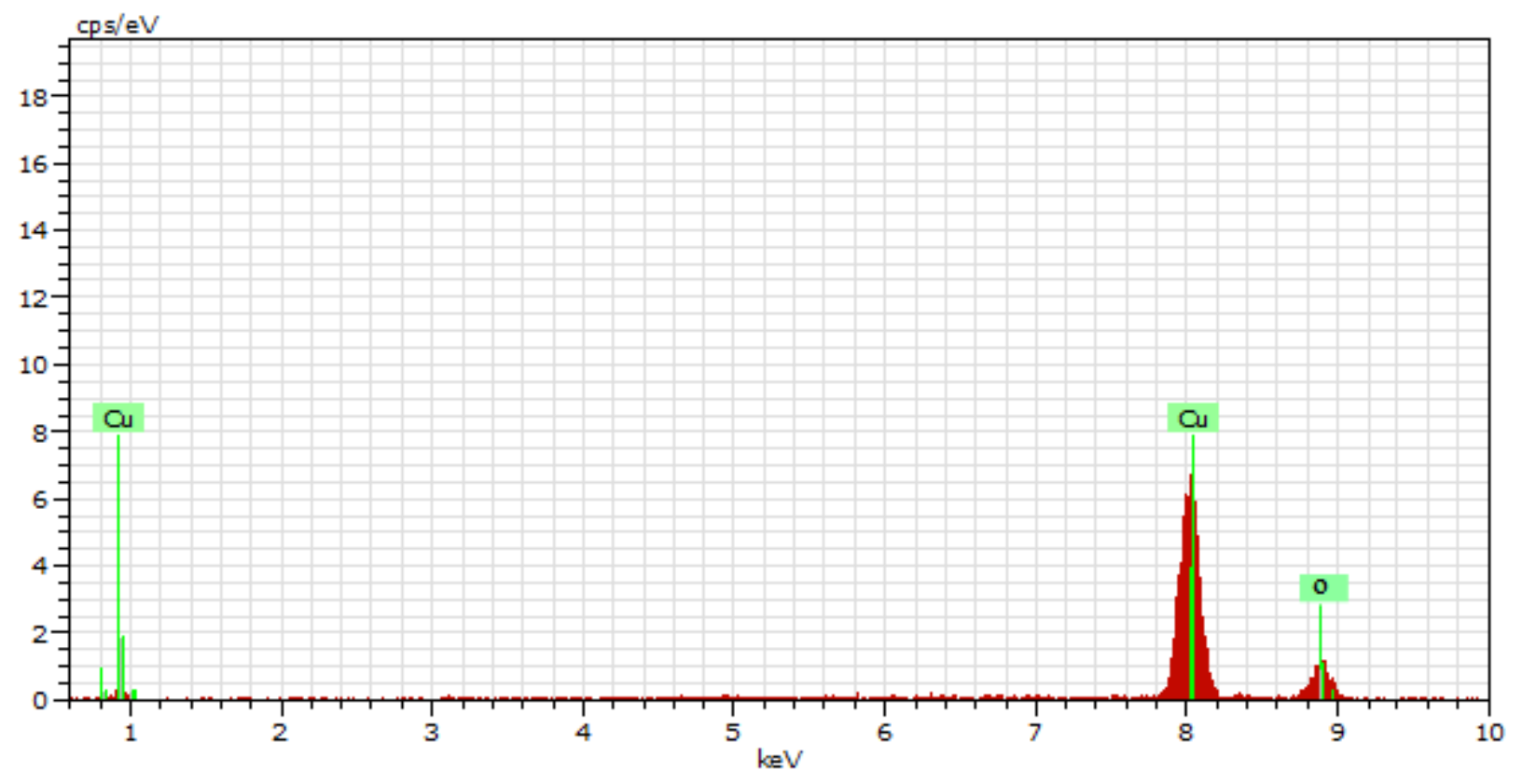

Fig. 3 EDX spectrum of $\mathrm{CuO}$ NTs

\section{FT-IR}

Further to check the important functional group and bonding frequencies, the prepared films were subjected to ATR-FT-IR (F1 to F3) and FT-IR for CuO NTs. Figure 6a corresponds to the $\mathrm{CuO}$ NTs peak at $3500 \mathrm{~cm}^{-1}$ due to the $\mathrm{OH}$ group present on the phytochemicals of leaf extract phenolic 
group, peak at $1700 \mathrm{~cm}^{-1}$ attributed to the presence of carbonyl group, and the peak at $509 \mathrm{~cm}^{-1}$ confirm the formation of $\mathrm{CuO}$ NTs [72]. Figure 6b corresponds to PVA composite films (F1, F2 and F3), all the films show peak at almost same position at $3300 \mathrm{~cm}^{-1}$ due to the $\mathrm{OH}$ stretching, peak at $2700 \mathrm{~cm}^{-1}$ and $2900 \mathrm{~cm}^{-1}$ due to C-H stretching of alkyl group, peak at $1769 \mathrm{~cm}^{-1}$ due to $\mathrm{C}=\mathrm{O}$ bond of PVA acetate group, peak at $1437 \mathrm{~cm}^{-1}$ due to $\mathrm{O}-\mathrm{H}$ symmetric bending, peak at 1272 $\mathrm{cm}^{-1}$ due to $\mathrm{C}-\mathrm{O}$ stretching, in film F2 and F3 peak at $532 \mathrm{~cm}^{-1}$ due to the presence of $\mathrm{Cu}-\mathrm{O}$ bond. In film F3, the strong broad peak at $1690 \mathrm{~cm}^{-1}$ due to the carboxylic group of Asp, this group involved formation of the complex reported in the literature [62].
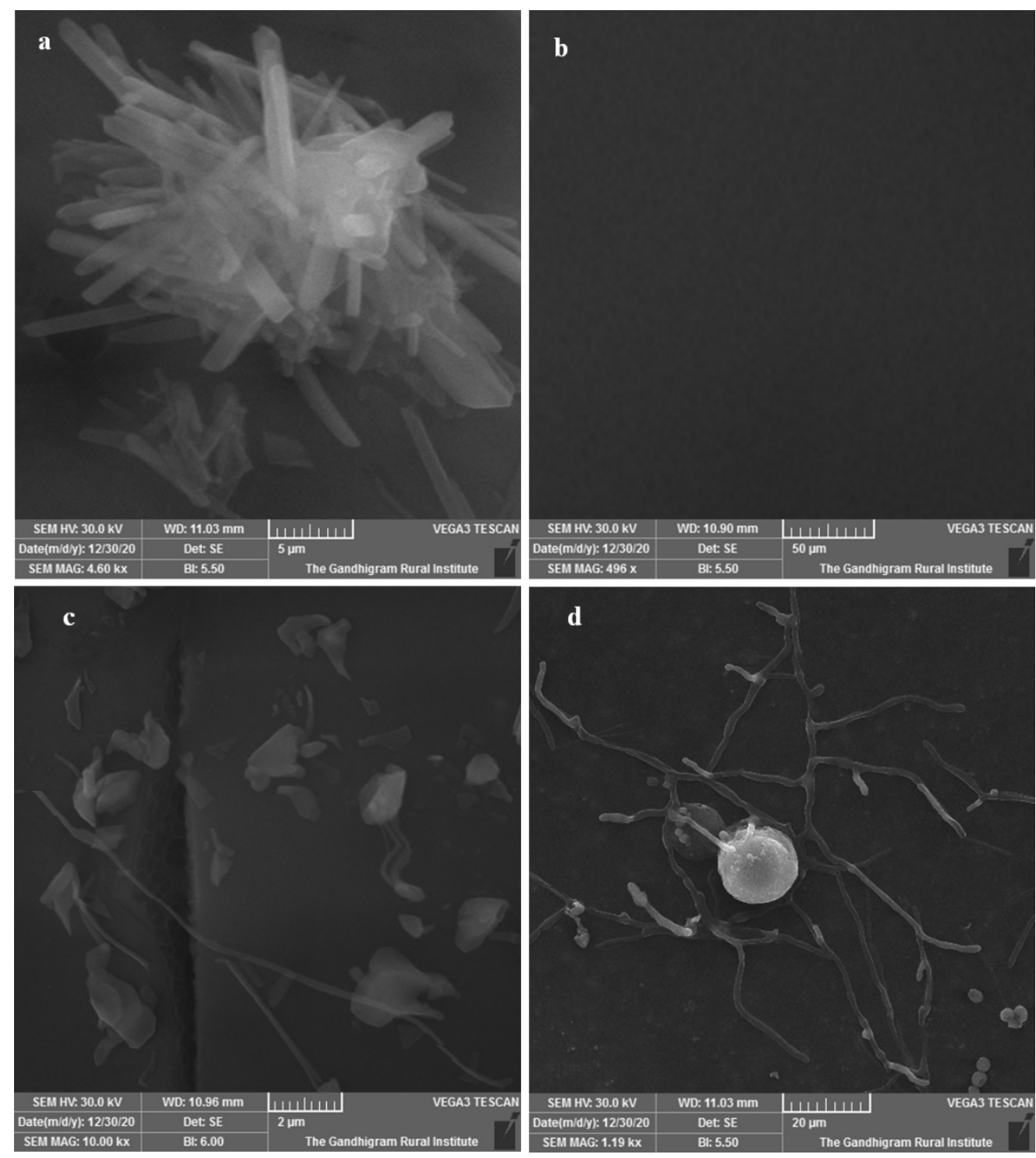

Fig. 4 SEM images, a) CuO NTs, b) F1, F2 and F3 


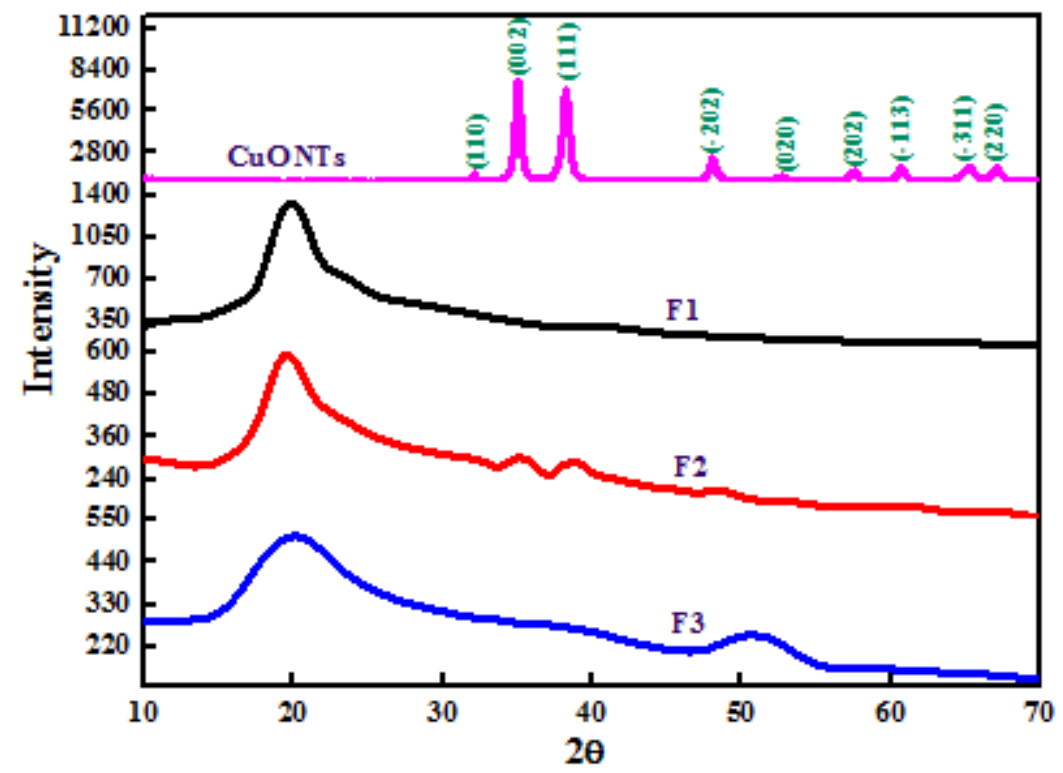

Fig. 5 XRD pattern of $\mathrm{CuO}$ NTs, F1, F2 and F3 films
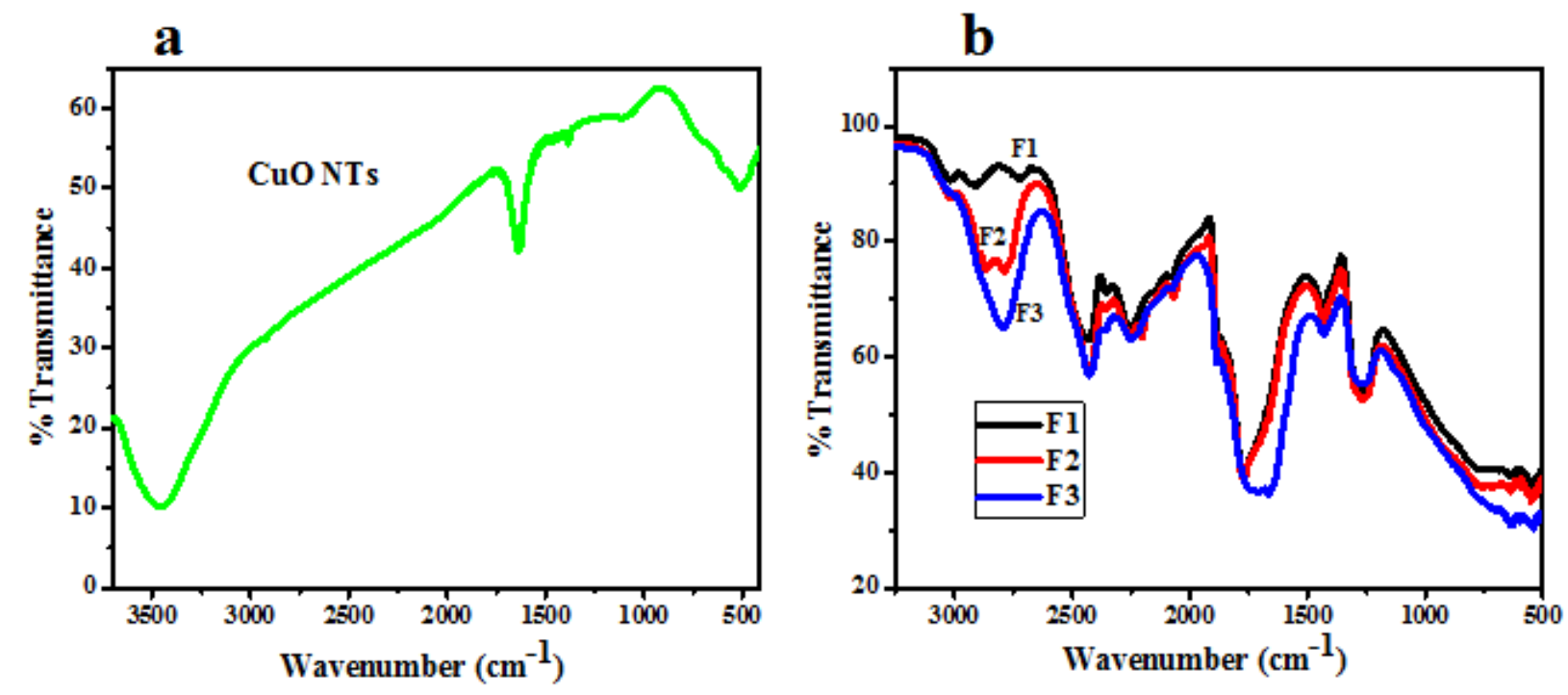

Fig. 6 a) FT-IR spectrum of CuO NTs and b) ATR-FT-IR of F1-F3 films

\section{Thickness of the film}

The thickness of the prepared films is measured using digital micrometer, and all films have an average thickness of $0.07 \mathrm{~mm}$. Among the three films, the film F1 having a lower thickness and F3 shows small increase in the thickness. The small increase in the thickness of the films from F1 to F3 observed due to the incorporation of the additive take part in the total composition. 


\section{Water contact angle (WCA)}

The surface wettability of the prepared composite films was analyzed by static contact angle measurement and summarized in Figure 7. The hydrophilic, hydrophobic, surface energy and selfcleaning nature of the prepared films F1, F2 and F3 were explained on the bases of WCA. The WCA of F1 film was found to be $69.5 \pm 4.1^{\circ}$, which indicate that, the film has hydrophilic surface. The author Salunkhe reported that Contact angle less than $90^{\circ}$ is hydrophilic, greater than $90^{\circ}$ is the hydrophobic and contact angles less than $90^{\circ}$ correspond to high wettability, while contact angles greater than $90^{\circ}$ correspond to low wettability [73]. The WCA of F2 \& F3 films were found to be $50.1 \pm 6.3^{\circ}$ and $39.8 \pm 2.9^{\circ}$ respectively, it shows that, the incorporation of CuO NTs and Asp onto a PVA enhances the hydrophilicity, surface wettability, surface energy and self-cleaning nature of the film surface. Relationship between photocatalytic activity, hydrophilicity, selfcleaning effect reported in the literature [74].

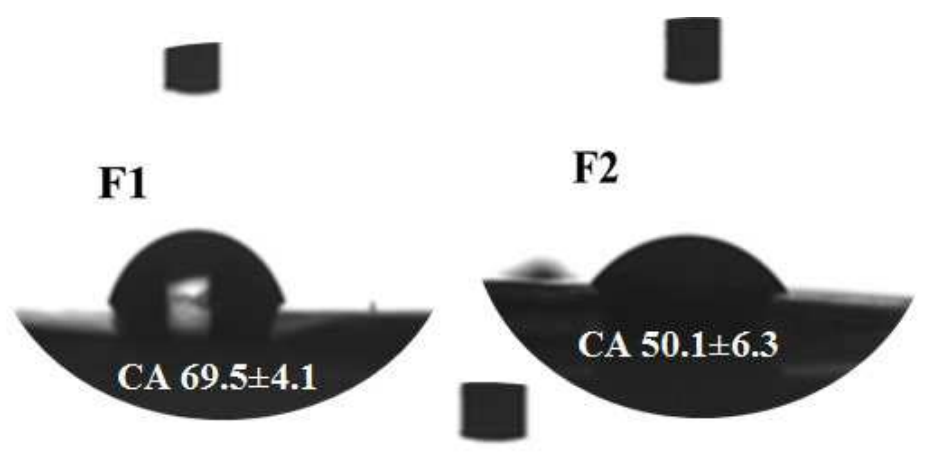

F3

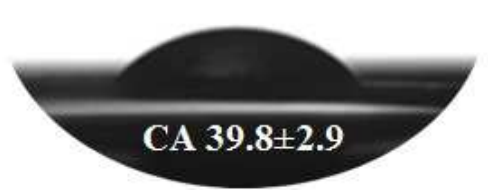

Fig. 7 Water Contact Angle of films; $F_{1}=69.5 \pm 4.1, F_{2}=50.3 \pm 16.3$ and $F_{3}=39.8 \pm 2.9$

\section{Optical properties}

\section{Optical absorption and transmission}

Figure 8a shows the UV-Vis absorption spectra of the PVA nanocomposite films. An absorption band of pure PVA is observed at $260 \mathrm{~nm}$, and it is assigned to $\pi-\pi^{*}$ electronic transition which may due to the acetate group in the PVA back bone or the semicrystalline nature of PVA. F2 film shows the large and broad absorbance peak at $264 \mathrm{~nm}$ due very good interaction between the $-\mathrm{OH}$ 
group of PVA and $\mathrm{CuO}$ NT. F3 film shows the large and broad two absorbance bands in range of $300 \mathrm{~nm}$ and $460 \mathrm{~nm}$ ( $\mathrm{n}-\pi^{*}$ transition indicates the presence of carbonyl group) due to the complex formation between $\mathrm{CuO}$ NTs and Asp, and it was confirmed by the formation of blue color of the film. The absorbance of the polymer prepared films increases with the addition of CuO NTs and Asp to the PVA, the absorption edge shifts towards higher wavelengths (red shift) [45]. The redshift of absorption edge of the composite films indicated hydrogen bonding between molecules of $\mathrm{CuO}$ NTs, PVA (-OH groups), Asp (- $\mathrm{NH}_{2},-\mathrm{COOH}$ groups), red shift is also for the increase in the crystallinity films with addition of CuO NTs and Asp to the PVA.

Figure $8 \mathrm{~b}$ shows the transmission spectra of PVA nanocomposite films. It is clear that, the transmission slight changes with the addition of $\mathrm{CuO}$ NTs and Asp to the PVA. This indicates very good transmission spectra in the UV region (200-250 nm) related to the PVA bandgap [75]. The practically good transmittance of the polymer films in the visible region $(400-800 \mathrm{~nm})$ is due to the normal dispersion of the light. This good result in the transmittance helpful in the photocatalytic degradation of MB dye.
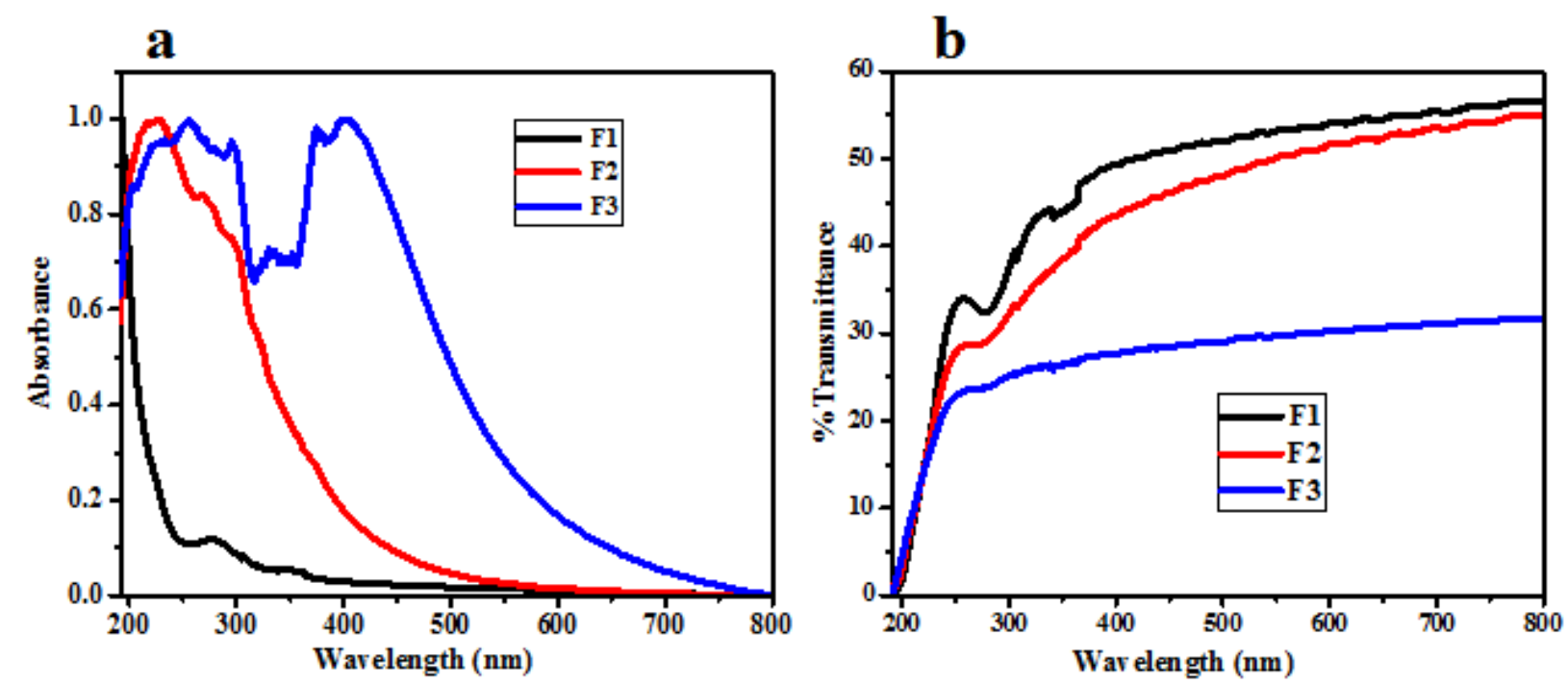

Fig. 8 a) UV-Vis absorption spectra for PVA nanocomposite films F1-F3. 8b) Transmittance spectra v/s Wavelength for PVA nanocomposite films F1-F3.

\subsubsection{Optical energy bandgap}

The optical absorption coefficient was investigated via photon energy to identify the band structure and the type of electron transition take place for the polymer nanocomposites using Tauc's power law (eq.2):

$$
\alpha h v=\mathrm{B}(\mathrm{hv}-\mathrm{Eg})^{n}----2
$$


where $\alpha$ is the absorption coefficient $(\alpha=2.303 \times \mathrm{A} / \mathrm{d}), \mathrm{A}$ is the absorbance, $\mathrm{d}$ is the polymer film thickness, hv is the incident photon energy, B is constant, Eg is the optical bandgap of the material, type of transitions allowed direct, allowed indirect, forbidden direct and forbidden indirect transitions and their exponent $n$ can be equal to $1 / 2,2,3 / 2$ or 3 respectively [45]. The direct optical band gap obtained by $(\alpha h v)^{2} \mathrm{v} / \mathrm{s}(\mathrm{hv})$ plot illustrated in Figure $9 \mathrm{a}$, it can be seen from the figure $9 \mathrm{a}$, the optical band gap for pure F1 is equal to $5.6 \mathrm{eV}$, which decreases to $3.0 \mathrm{eV}$ for F2 and $2.3 \mathrm{eV}$ for F3. The indirect optical band gap obtained by $(\alpha h v)^{1 / 2} \mathrm{v} / \mathrm{s}(\mathrm{hv})$ plot is illustrated in Figure $9 \mathrm{~b}$, it can be seen from the figure $9 \mathrm{~b}$ that, the optical band gap for pure $\mathrm{F} 1$ is equal to $5.3 \mathrm{eV}$, which decreases to $2.7 \mathrm{eV}$ for F2 and $2.1 \mathrm{eV}$ for F3. In both direct and indirect band gaps, the decrease in the optical band gap from F1-F3 is an indicator of the change in the structure of the polymer matrix and is associated with the creation of localized state in the bandgap [76]. This decreased bandgap is very much necessary to enhance the photocatalytic activity of the film.
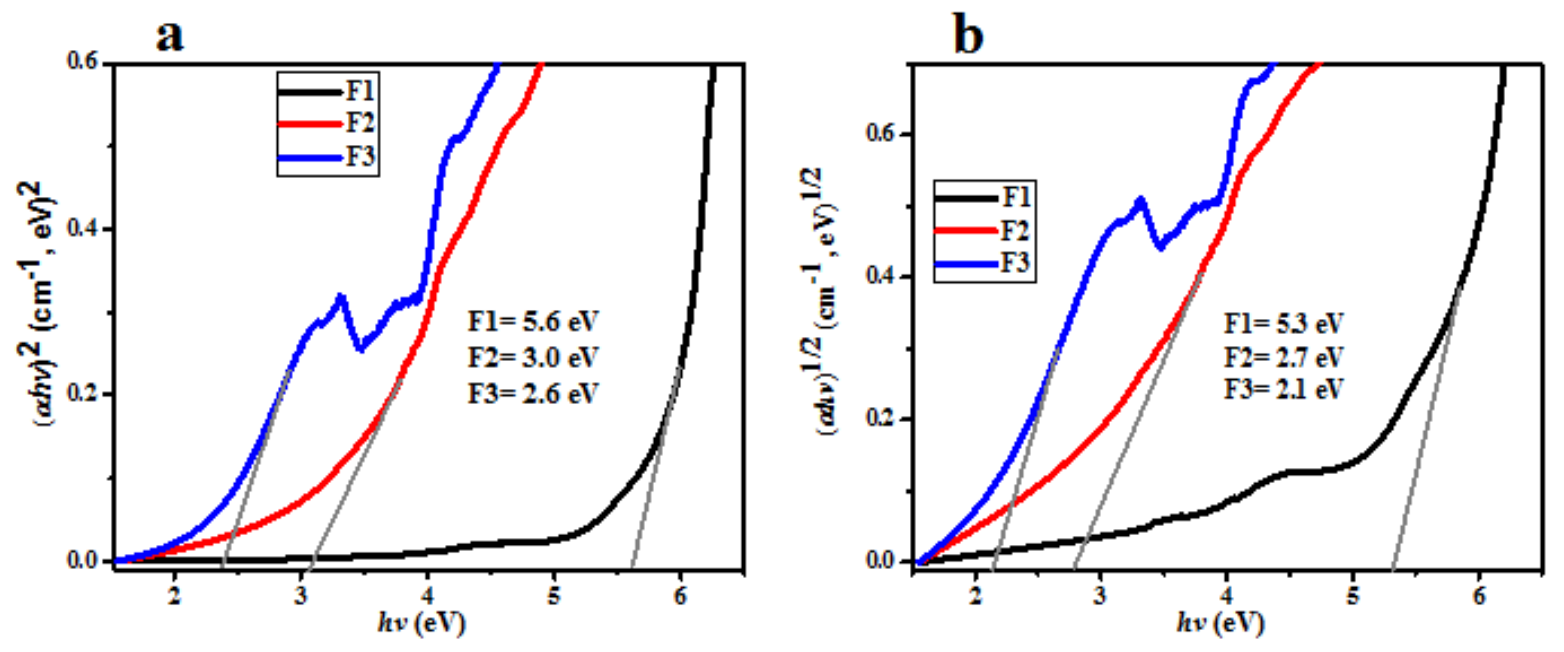

Fig. 9 The plots of (a) direct $\left[(\alpha h v)^{2}\right.$ vs. (hv) $]$ and (b) indirect $\left[(\alpha h v)^{1 / 2}\right.$ vs. (hv)] optical band gaps polymer nanocomposite films F1-F3

\subsubsection{Extinction coefficient and refractive index}

The most important parameters of optical application are the refractive index (n) and the extinction coefficient $(\mathrm{k})$. These optical parameters were determined from the reflectance and absorption coefficient $(\alpha)$ data according to the following equations 3, 4 and 5:

$$
\begin{gathered}
k=\frac{\alpha \lambda}{4 \pi}----3 \\
n=\frac{1+\sqrt{R}}{1-\sqrt{R}}---4
\end{gathered}
$$




$$
R=1-(\sqrt{T * \exp (A)}------5
$$

Where $\mathrm{R}$ is the reflectance calculated from the transmission (T) and absorption (A) data. Soliman, et al., reported the extinction coefficient decreases with increase of wavelength in the UV region, the incident photon has high energy in the UV region and this energy is enough to excite electrons to overcome the band gap to transfer electron from the valence band to the conduction band. While, in the visible region $(400-800 \mathrm{~nm})$, the $\mathrm{k}$ value increases with the increase in the wavelength of the incident light, this can be because of the photon energy is unable to excite electron from one state to another state, and this energy can be lost due to scattering or reflection by polymer films [77]. But in our present work (Figure 10a), the extinction coefficient decreases continued in the visible region also (extinction coefficient of film F2 decreases up to $430 \mathrm{~nm}$, film F3 decreases up to $600 \mathrm{~nm}$ of the visible region), due to this, incident photon have enough energy in the visible region and this energy is enough to excite electrons to overcome the band gap (to transfer electrons from the valence band to the conduction band), due to this reason, the prepared films showed effective photocatalytic degradation of MB in the visible light.
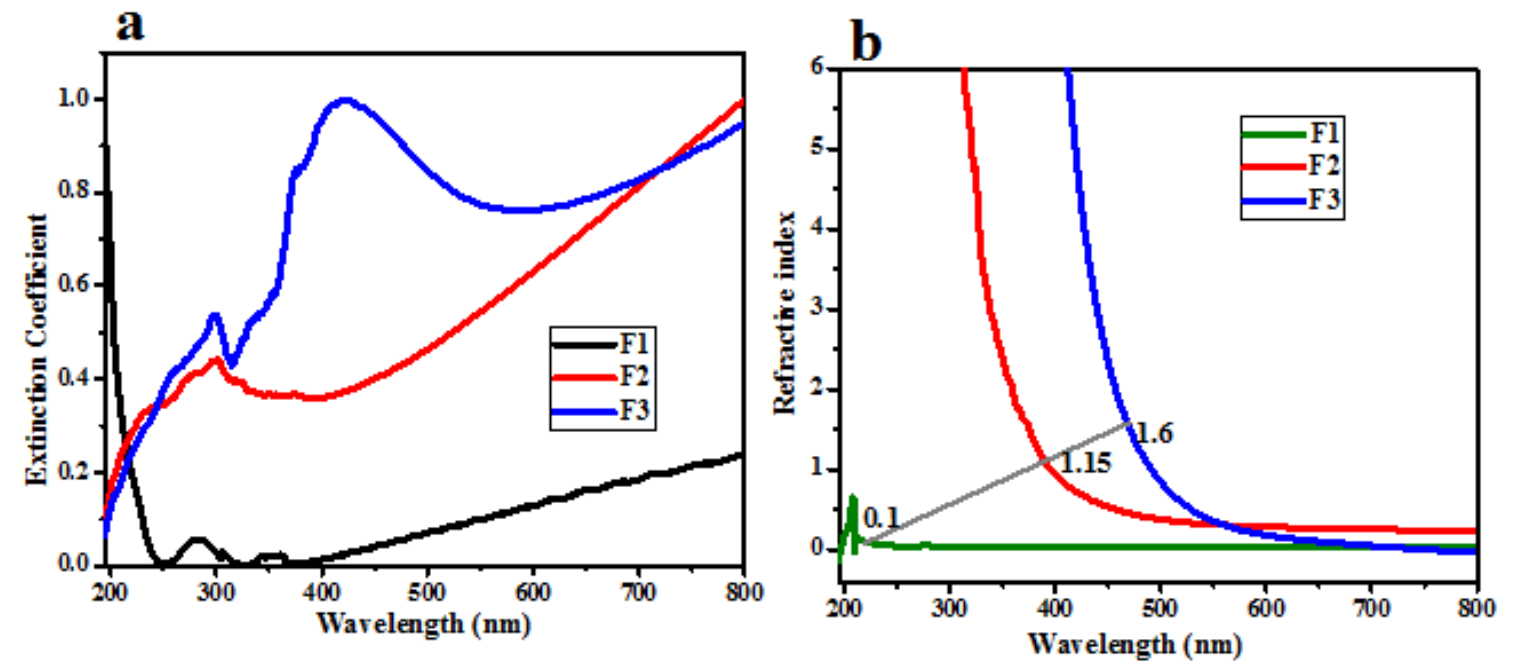

Fig. 10, a) Extinction coefficient vs. the wavelength of the PVA nanocomposite films F1-F3. b) Refractive index vs. the wavelength of the PVA nanocomposite films F1-F3.

Figure 10b. shows the dependences of the refractive index on the wavelength for PVA polymer nanocomposite films. It is evident that $\mathrm{n}$ values increase $(\mathrm{F} 1=0.1, \mathrm{~F} 2=1.15$ and $\mathrm{F} 3=1.6)$ as the addition of $\mathrm{CuO}$ NTs and Asp. This is associated with the high density with which CuO NTs and ASP are packed in the polymer matrix. The increase in refractive index (n) is assigning the material optical systems and electronic features [78]. 


\section{Sorption and photocatalytic degradation of MB dye}

The prepared composite films and $\mathrm{CuO}$ NTs were evaluated for their photocatalytic performance of the dye MB degradation by exposure to sunlight shown in the Figures 12a-12e. There was no MB degradation observed in the absence of the catalysts, which indicated the stability of the MB under self-photolysis [79]. The prepared film F3 have a negatively charged surface with carboxylic and amine groups, as well as a $\mathrm{pH}$ of 7-9 (based on individual substrate $\mathrm{pH}$ ), which enhances the adsorption of cation species due to electrostatic attraction between the composite film negative charge surface and the positive charge on the MB dye. The net sunlight irradiation time was exposed up to $70 \mathrm{~min}$, and the absorption intensity measured at $664 \mathrm{~nm}$, and the absorption intensity was monitored for every $10 \mathrm{~min}$ interval. The results revealed that, the bare $\mathrm{CuO}$ NTs and F1 film shows low photocatalytic activity against degradation of the MB for 70 min and 50 min was 52\% and 20\% respectively. Meanwhile F2 and F3 nanocomposite films gave much higher degradation of $74.99 \%$ and $77.15 \%$ respectively compared to PVA and CuO NTs alone (Figure 11). The experimental data revealed that, the photocatalytic activity of $F 1$ boosts with the addition of $\mathrm{CuO}$ NTs and Asp. The film F3 composite degraded dye $77.15 \%$ in 50 min and F2 took $74.99 \%$ in 70 min dye degradation. This is because of strong interaction and complex formation between the $\mathrm{CuO}$ NTs and Asp in film F3 (confirmed by the color change to blue in the film and FTIR spectra), which enhanced photocatalytic activity.

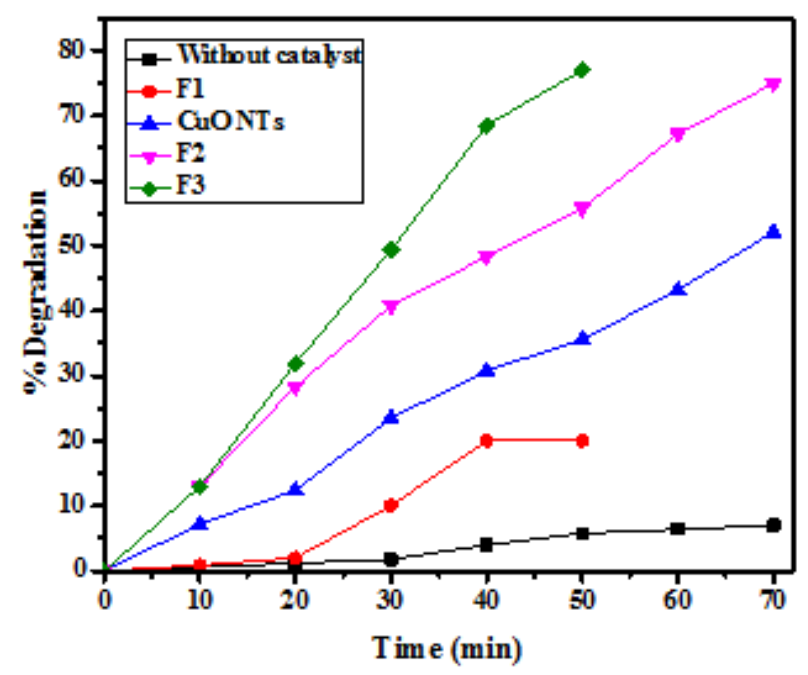

Fig. 11 Percentage degradation of MB; catalyst free, and in the presence of CuO NTs, F1, F2 and F3 

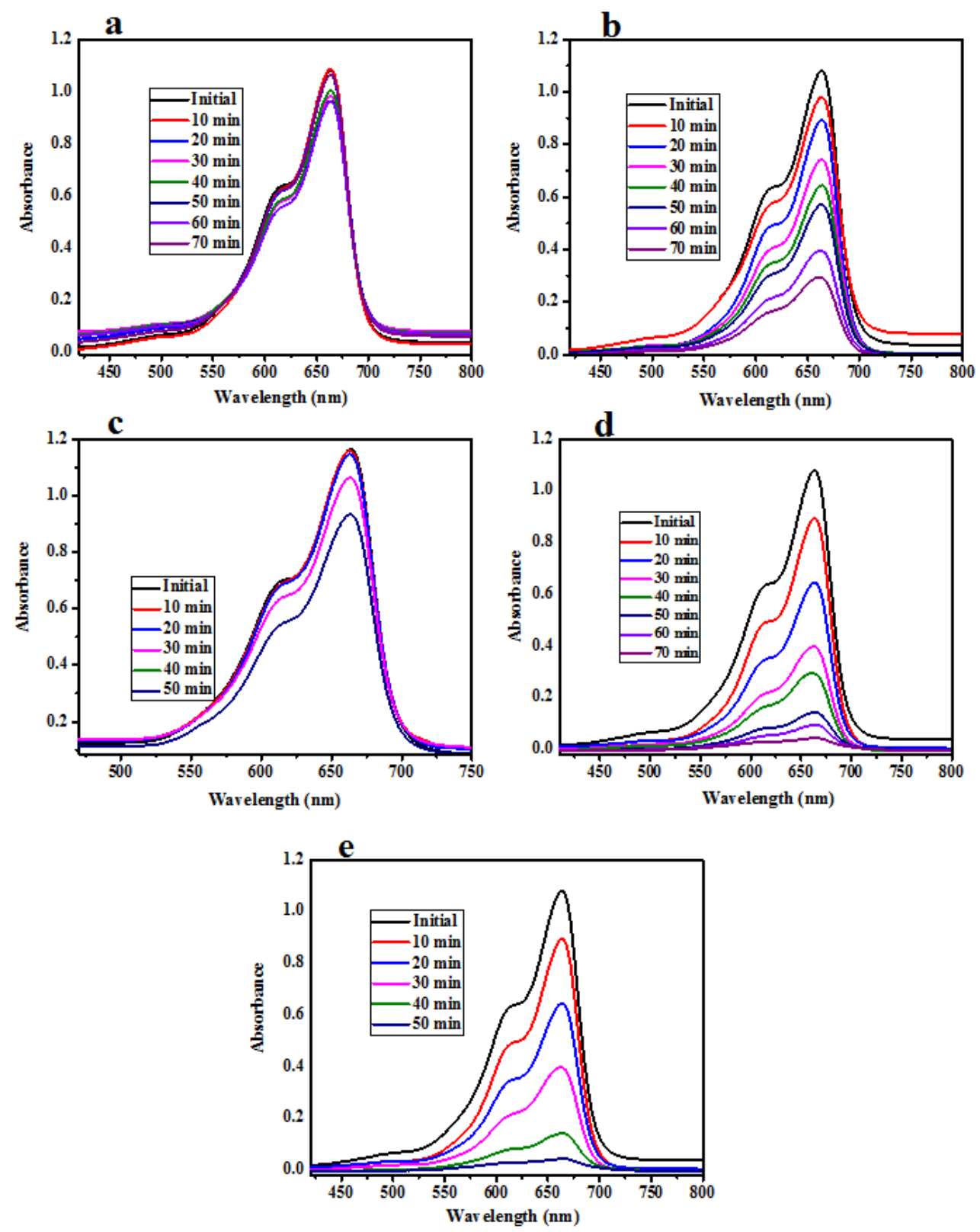

Fig. 12 Changes in the UV-Vis absorption spectra of MB aqueous solution in the presence of (a) Without catalyst, (b) CuO NTs, (c) PVA, (d) PVA-CuO NTs, and (e) PVA-CuO NTs-Asp composite films.

\section{Adsorption isotherms and kinetic model}

Langmuir, Freundlich, and pseudo-second-order reaction [13] with well-fitted models for the dye degradation studies are shown in Figures 13a-13c and results data is given in Table 1. A detailed explanation of adsorption isotherm and kinetic model studies are given below. 


\section{Adsorption isotherms:}

Several models have been reported in the literature to describe the equilibrium adsorption systems. However, in this present study, the two classical models of Langmuir and Freundlich were tested. Langmuir isotherm model:

It is proper for monolayer adsorption on a surface and is expressed as

$$
q_{e}=q_{m} K_{L} \cdot \frac{C_{e}}{1+K_{L} C_{e}}----6
$$

$q_{m}$ and $K_{L}$ are the constants of Langmuir equation,

The linear form of Langmuir isotherm is

$$
\frac{1}{q_{e}}=\frac{1}{q_{m}}+\frac{1}{q_{m} K_{L} C_{e}}----7
$$

Where Ce is the equilibrium concentration ( $\mathrm{mg} / \mathrm{L}), \mathrm{q}_{\mathrm{e}}$ the amount of MB adsorbed $(\mathrm{mg} / \mathrm{g}), \mathrm{q}_{\mathrm{m}}$ is the maximum quantity of adsorption $(\mathrm{mg} / \mathrm{g}), \mathrm{K}_{\mathrm{L}}$ is sorption equilibrium constant $(\mathrm{L} / \mathrm{mg})$. The values of $q_{m}$ and $K_{L}$ were calculated from slope and intercept of Langmuir plot of $1 / q_{e}$ versus $1 / C_{e}$. as shown in Table 1.

A dimensionless constant separation factor (RL) of Langmuir isotherm was used to determine the favorability of the adsorption process. RL is defined in eq. 8, the values of RL indicate the type of isotherm to be irreversible $(\mathrm{RL}=0)$, favorable $(0<\mathrm{RL}<1)$, linear $(\mathrm{RL}=1)$ or unfavorable $(\mathrm{RL}>$ 1).

$$
R L=\frac{1}{1+K_{L} C_{0}}----8
$$

From the data calculated in Table 1, all the calculated RL values are greater than 0 but less than 1 indicating that Langmuir isotherm is favorable.

Freundlich isotherm model:

$$
q_{e}=K_{F} C_{e}{ }^{1 / n}-----9
$$

where $\mathrm{K}_{\mathrm{F}}=$ Freundlich isotherm constant $(\mathrm{mg} / \mathrm{g}), \mathrm{n}=$ adsorption intensity, $\mathrm{Ce}=$ the equilibrium concentration of adsorbate $(\mathrm{mg} / \mathrm{L}), \mathrm{q}_{\mathrm{e}}=$ the amount of metal adsorbed per gram of the adsorbent at equilibrium $(\mathrm{mg} / \mathrm{g})$.

The linear form of Freundlich isotherm is

$$
\ln q_{e}=\ln K_{F}+\frac{1}{n} \ln C_{e}-----10
$$


The values of $n$ and $K_{F}$ calculated from plot of $l n q_{e}$ versus $\ln C e$ as shown in Table 1. 1/n are Freundlich constants related to the multilayer adsorption capacity and the surface heterogeneity respectively. When $(1 / \mathrm{n}>1)$ the adsorption is unfavorable, $(1 / \mathrm{n}=1)$ the adsorption is homogeneous and $(0<1 / \mathrm{n}<1)$ the adsorption is favorable. From the data in table 1 , all the calculated values of $1 / \mathrm{n}$ are less than 1 , indicating that the sorption of $\mathrm{MB}$ onto $\mathrm{CuO}$ NTs is favorable.

Adsorption kinetics

Pseudo-second-order model is represented as:

$\frac{d q_{t}}{d_{t}}=K\left(q_{e}-q_{t}\right)^{2}-----11$

Where $\mathrm{q}_{\mathrm{e}}$ is the amount of ion sorbed at equilibrium $(\mathrm{mg} / \mathrm{g}), \mathrm{q}_{\mathrm{t}}$ is the amount of ion sorbed at time $\mathrm{t}(\mathrm{mg} / \mathrm{g})$, and $\mathrm{k}$ is the rate constant of the pseudo-second order kinetic model of adsorption $(\mathrm{g} / \mathrm{mg}$ min). In Fig. 13c the plot of $t / q t$ versus $t$ is straight line, from which qe and $\mathrm{k}$ can be determined from the slope and the intercept of the line as shown in Table 1. In the Table 1 all the calculated $\mathrm{R}^{2}$ value is 0.999 proving that the sorption data fitted well to the pseudo-second-order model.
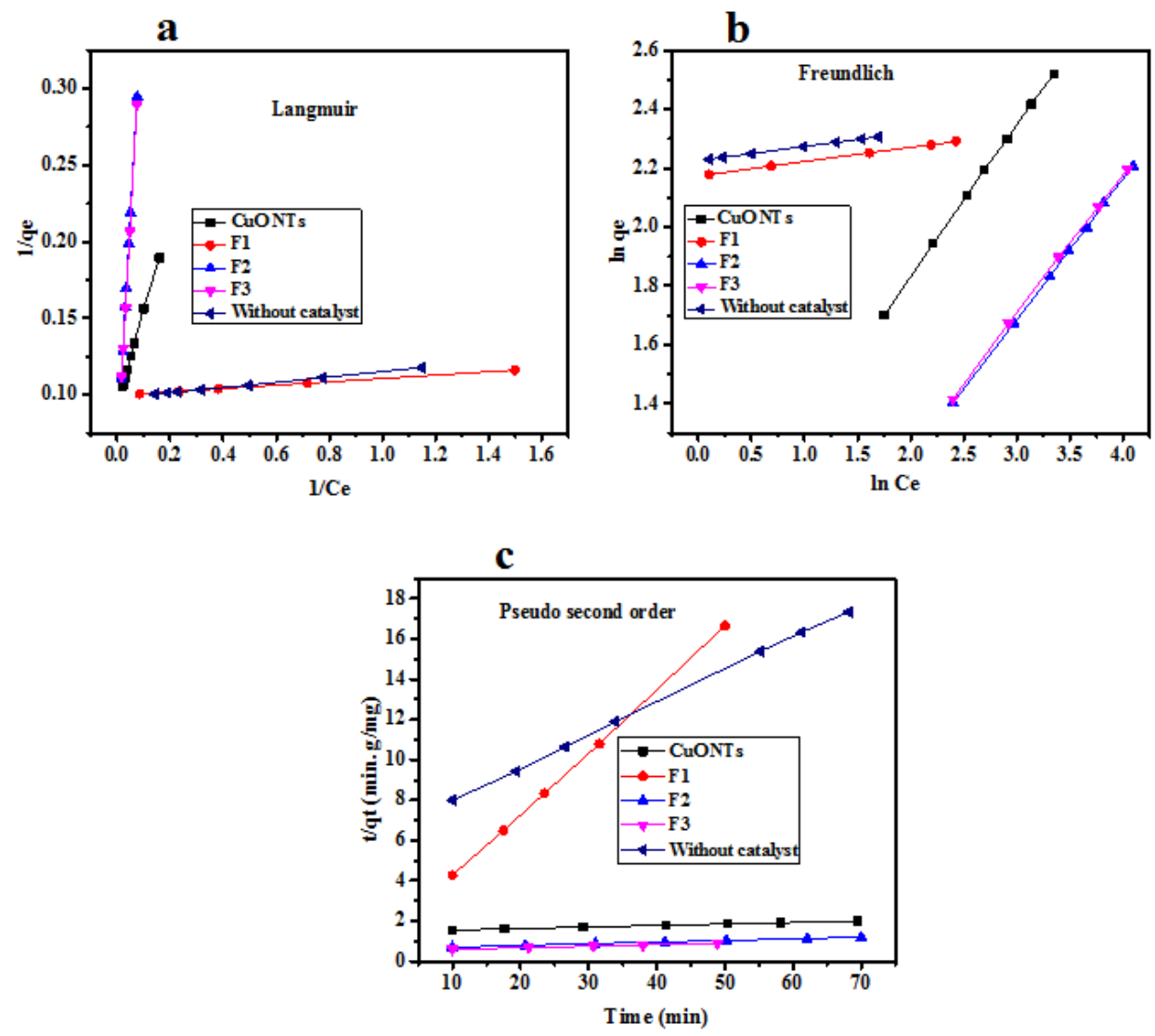

Fig. 13 a) Langmuir model, b) Freundlich model and c) Pseudo second order model for the different photocatalysts 
Table 1. Adsorption isotherm models and kinetic model data.

\begin{tabular}{lllllllllllll} 
Model & \multicolumn{3}{c}{ Langmuir } & \multicolumn{3}{c}{ Freundlich } & \multicolumn{3}{c}{ Pseudo second order } \\
Parameters & $\mathrm{q}_{\mathrm{m}} /\left(\mathrm{mg} \cdot \mathrm{g}^{-1}\right)$ & $\mathrm{k}_{\mathrm{L}} /\left(\mathrm{L} \cdot \mathrm{mg}^{-1}\right)$ & $\mathrm{R}^{2}$ & $\mathrm{R}_{\mathrm{L}}$ & $\mathrm{k}_{\mathrm{F}}$ & $1 / \mathrm{n}$ & $\mathrm{R}^{2}$ & $\mathrm{q}_{\mathrm{e}}\left(\mathrm{mg} \cdot \mathrm{g}^{-1}\right)$ & $\mathrm{k}_{2} /\left(\mathrm{g} \cdot \mathrm{mg}^{-1} \cdot \mathrm{min}^{-1}\right)$ & $\mathrm{R}^{2}$ \\
Without catalyst & 0.90 & 66.66 & 0.999 & 0.014 & 0.958 & 0.04786 & 0.999 & 3.12 & 0.0041 & 0.999 \\
F1 & 4.02 & 22.61 & 0.999 & 0.039 & 0.931 & 0.06158 & 0.999 & 10.89 & 0.085 & 0.999 \\
CuO NTs & 10.72 & 0.152 & 0.998 & 0.860 & 0.887 & 0.3157 & 0.999 & 39.12 & 2.877 & 0.999 \\
F2 & 16.64 & 0.0193 & 0.999 & 0.978 & 0.807 & 0.4746 & 0.999 & 74.96 & 3.104 & 0.999 \\
F3 & 17.28 & 0.0187 & 0.999 & 0.981 & 0.746 & 0.4768 & 0.999 & 110.18 & 4.946 & 0.999
\end{tabular}

\section{Photocatalytic mechanism}

The superior photocatalytic activity of the PVA/CuO NTs/Asp composite film under Sun light may be ascribed due to its by: (i) strong interaction between the CuO NTs and Asp, (ii) reducing the band gap by creation of localized state in the bandgap, (iii) enhance the efficiency of photogenerated electron-hole pair separation, (iv) very good adsorption ability, (v) decreased extinction coefficient in the visible region due to this, incident photon have enough energy in the visible region and this energy is enough to excite electrons to overcome the band gap, (vi) optically transparent.

$\mathrm{CuO} \mathrm{NTs}+h v \rightarrow h^{+}+e^{-}(\mathrm{CuO}$ NTs pristine $)$

And

$\mathrm{CuO}$ NTs-Asp $+h v \rightarrow h^{+}+e^{-}$(Composites)

The possible mechanisms can be put forward for the degradation of MB by the prepared composites and $\mathrm{CuO}$ NTs under visible light irradiation (Figure 14) which may proceed through dye sensitization and CuO NTs-Asp sensitization. During sensitization, MB must be adsorbed onto the surface of the composite film. The adsorbed $\mathrm{MB}$ and $\mathrm{CuO}$ NTs-Asp will absorb visible light and get excited from its ground state to its excited state and migrated to the conduction band (CB) generating holes on the VB (Figure. 14). The generated holes in the VB react directly with the organic dye $(\mathrm{MB})$ or with the surrounding water molecules to generate hydroxyl radicals $(\bullet \mathrm{OH})$. The electrons collected on the $\mathrm{CB}$ react with the surrounding water and oxygen molecules to generate hydroxyl $(\cdot \mathrm{OH})$ and superoxide radicals $\left(\cdot \mathrm{O}_{2}^{-}\right)$. In such a way, produced radicals and holes are able to contribute essentially to the degradation of the color MB and other natural toxins, within the extreme response of the photodegradation of the $\mathrm{MB}$, the final products of the response are $\mathrm{CO}_{2}$ and $\mathrm{H}_{2} \mathrm{O}$ [80]. 

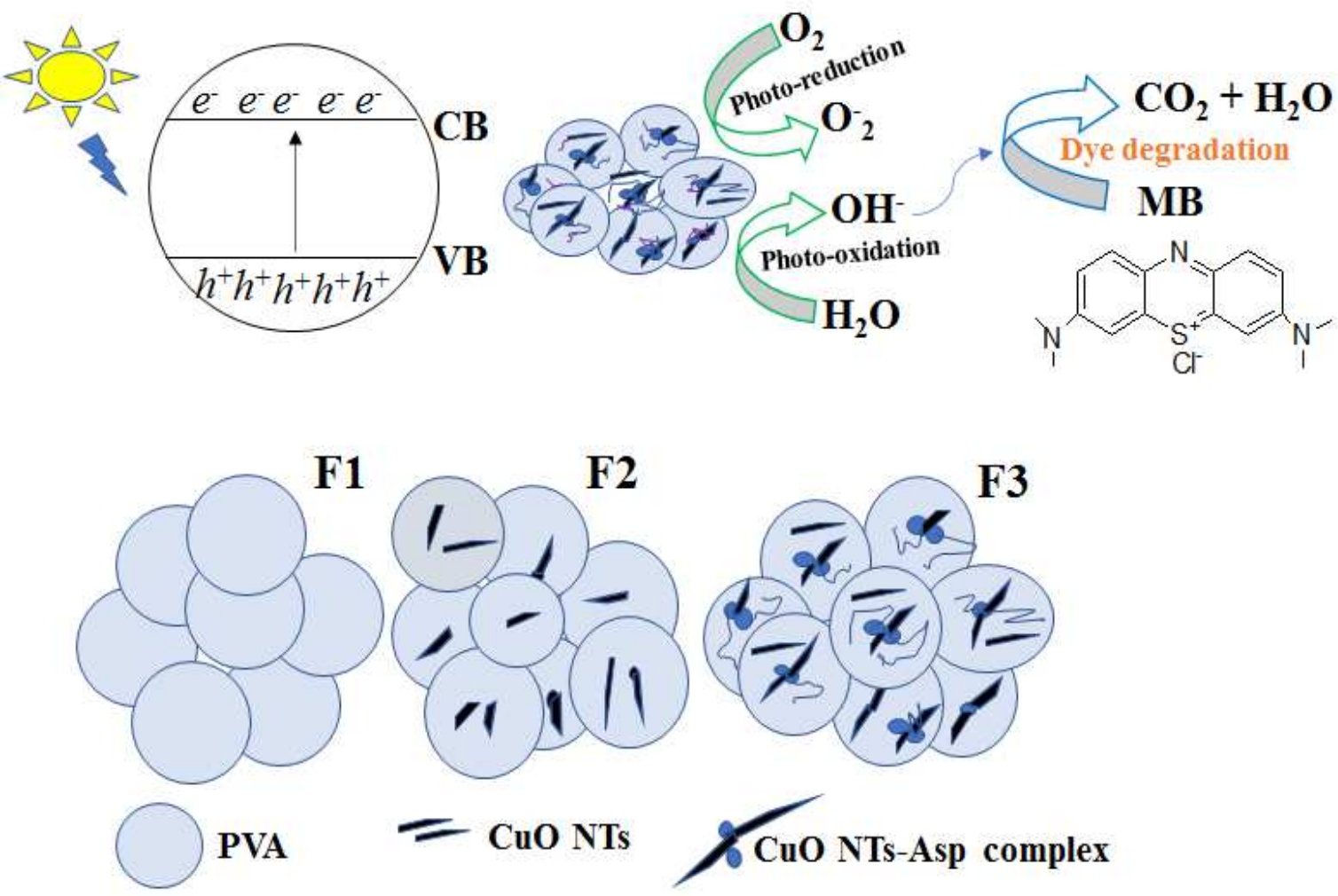

Fig. 14 Representation of photodegradation pathway of the dye MB.

Degraded product characterization by LC-MS

After sun light degradation of the MB, sample was concentrated to reduce the volume and resulted sample subjected to liquid chromatography-mass spectrometry (LC-MS) [81]. The standard dye sample and degraded sample of the MB mass spectra, and possible mechanism is shown in Figure 15a. It is clear that, the prominent peak at $319.9 \mathrm{Da}$, which is molecular weight of the MB dye. But the spectrum (Figure 15b) obtained after 50 min introduction to sunlight of the MB with film F3 revealed, the degradation of MB takes into molecules. From this consideration, it is cleared that, the intensity of MB peak is decreased with regard to time and form a degraded product as compared to standard MB peak intensity and plausible degradation pathways is laid out in Scheme 1. 

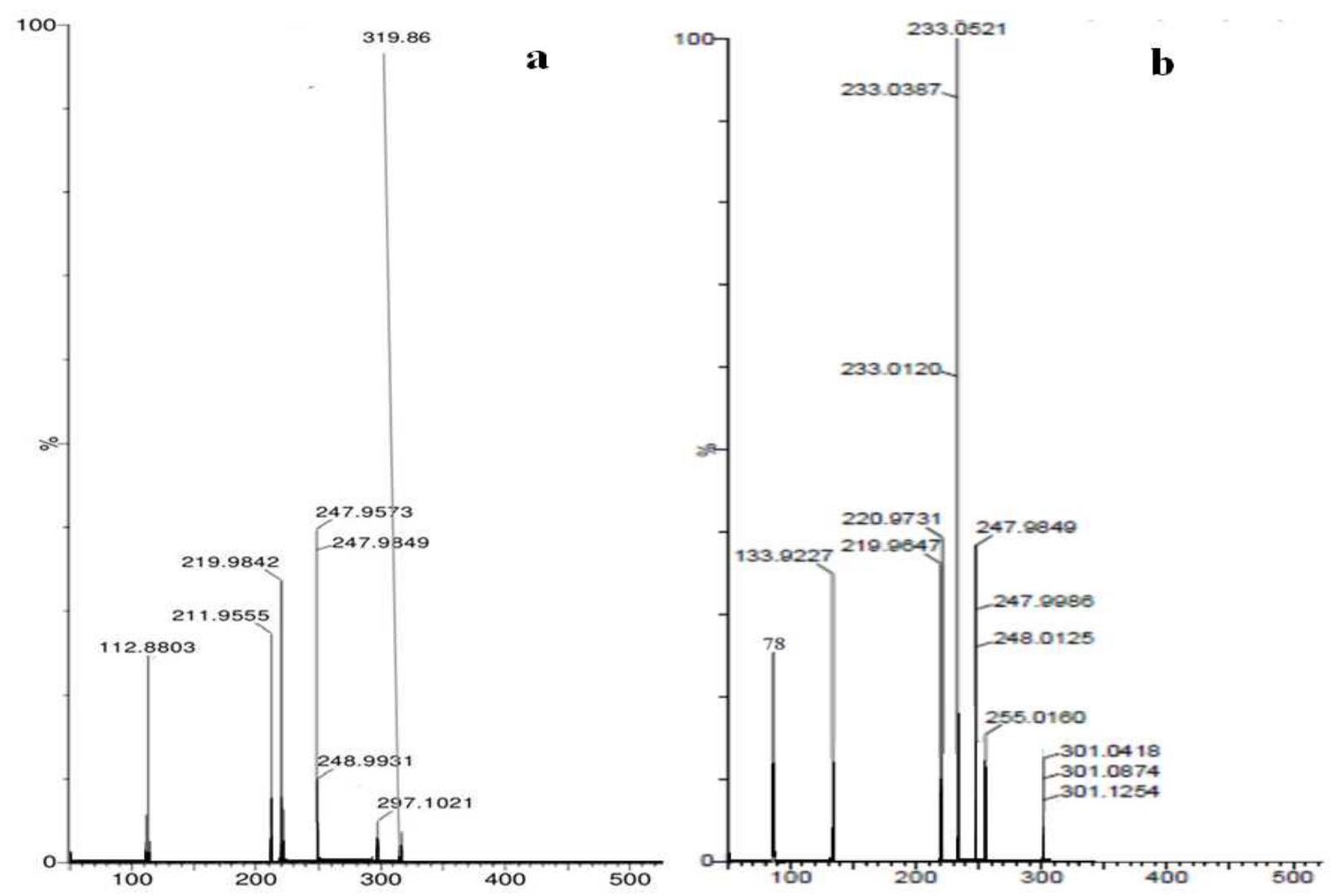

Figure 15. LC-MS product of: a) before degradation of the dye MB and b) after degradation of dye MB.

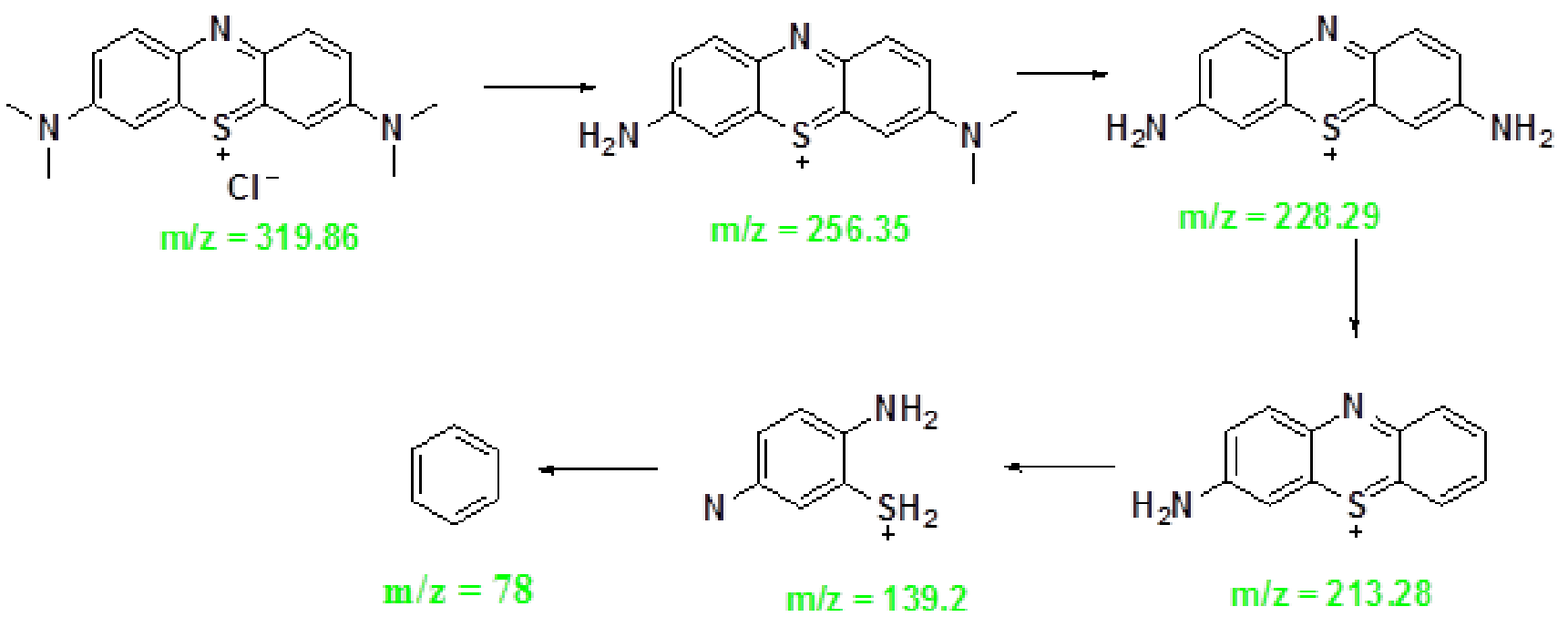

Scheme 1. Possible degradation pathway of MB (LC-MS model). 


\section{Conclusion}

In this work, we have demonstrated biogenic synthesis of $\mathrm{CuO}$ NTs and preparation of PVA nanocomposite films by means of solution casting method and structural aspects, physical morphology and water contact angle properties of PVA nanocomposite films were studied using various techniques. The prepared films show good optical property, adsorption and photocatalytic degradation of MB dye. The adsorption behavior of the PVA nanocomposite films studied by Langmuir, Freundlich and pseudo second order kinetics. The photocatalytic activities of the $\mathrm{CuO}$ NTs, PVA and PVA nanocomposite films are examined for the methylene blue (MB) degradation, and film PVA/CuO NTs/Asp showed highest (up to 77\%) degradation compared to other films in 50 min time duration. The improved photocatalytic attributed to its narrow band gap, improved utilization of sunlight and enhanced adsorption of dye due to the functional groups, greater active sites, high surface activity and semiconducting nature of $\mathrm{CuO}$ NTs and Asp embedded in PVA matrix. The photocatalytic degradation of MB by the PVA nanocomposite film was found to be influenced by hydroxyl radicals $(\cdot \mathrm{OH})$ and superoxide radicals $\left(\cdot \mathrm{O}_{2}{ }^{-}\right)$. The prepared PVA nanocomposite films could find use in photocatalytic removal of toxic organic contaminants from wastewater due to its simplicity, self-cleaning nature and low cost.

\section{Conflict of interest}

Authors are not having any conflicts to declare

Supporting information: Further SEM images, Biodegradable test, water vapor transmission rate, moisture retention capability properties of the prepared films (Figures S1-S7) given in the supporting information.

\section{Acknowledgement}

Authors are thankful to UGC for the award of Major Research Project and VGST, Govt. of Karnataka for SMYSR award and K-FIST-Level-II for financial support to KK.

\section{Reference}

1.Z. Huangfu, H. Hu, N. Xie, Y. Q. Zhu, H. Chen, and Y. Wang, Petrol Sci. 17, 1180 (2020).

2. A. Gallego-Schmid and R. R. Z. Tarpani, Water Research. 153, 63 (2019).

3. B. Lellis, C. Z. Fávaro-Polonio, J. A. Pamphile, and J. C. Polonio, Biotechnol. Res. Innov. 3, 275 (2019).

4. M. Rafatullah, O. Sulaiman, R. Hashim, and A. Ahmad, J. Hazard. Mater. 177, 70 (2010). 
5. R. Dod, G. Banerjee, and D. R. Saini, Clean Technol Environ Policy. 17, 2349 (2015).

6. H. Liu, C. Wang, and G. Wang, Chem. Asian J. 15, 3239 (2020).

7. G. Palmisano, V. Augugliaro, M. Pagliaro, and L. Palmisano, ChemComm. 3425 (2007).

8. H. Dong, G. Zeng, L. Tang, C. Fan, C. Zhang, X. He, and Y. He, Water Res. 79, 128 (2015).

9. M. J. Sampaio, C. G. Silva, R. R. N. Marques, A. M. T. Silva, and J. L. Faria, Catal. 161, 91 (2011).

10. F. F. Wang, Q. Li, and D. S. Xu, Adv. Energy Mater. 7, 1 (2017).

11. S. J. A. Moniz, S. A. Shevlin, X. An, Z. X. Guo, and J. Tang, Chem. Eur. J. 20, 15571 (2014).

12. C. H. Cao and L. Xiao, Adv Mat Res. 1015, 623 (2014).

13. A. G. El-Shamy and H. S. S. Zayied, Synth. Met. 259, 116218 (2020).

14. M. M. Rahman Khan, M. Akter, M. K. Amin, M. Younus, and N. Chakraborty, J Polym Environ. 26, 3371 (2018).

15. J. Selvi, S. Mahalakshmi, and V. Parthasarathy, JIOPM. 27, 1918 (2017).

16. S. F. Bdewi, O. G. Abdullah, B. K. Aziz, and A. A. R. Mutar, JIOPM. 26, 326 (2016).

17. S. M. Hosseini, H. Hosseini-Monfared, and V. Abbasi, Appl. Organomet. Chem. 31, 1 (2017).

18. A. A. Adewunmi, S. Ismail, and A. S. Sultan, JIOPM. 26, 717 (2016).

19. J. C. Yu, J. Yu, W. Ho, and J. Zhao, J. Photochem. Photobiol. A. 148, 331 (2002).

20. M. Boutamart, S. Briche, K. Nouneh, S. Rafqah, Y. Agzenai, ChemistrySelect. 2020, 5, 8522.

21. W. Guo, J. Liu, P. Zhang, L. Song, X. Wang, and Y. Hu, Compos Sci Technol. 158, 128 (2018).

22. N. Ben Halima, RSC Adv. 6, 39823 (2016).

23. A. El-Khodary, Physica B Condens. 405, 3401 (2010).

24. C. F. Mok, Y. C. Ching, F. Muhamad, N. A. Abu Osman, N. D. Hai, and C. R. Che Hassan, J Polym Environ. 28, 775 (2020).

25. K. S. Hajeeassa, M. A. Hussein, Y. Anwar, N. Y. Tashkandi, and Z. M. Al-Amshany, Nanobiomedicine. 5, 1 (2018).

26. M. F. Zayed, W. H. Eisa, and B. Anis, Desalin Water Treat. 57, 18861 (2016).

27. U. Habiba, M. S. Islam, T. A. Siddique, A. M. Afifi, and B. C. Ang, Carbohydr. Polym. 149, 317 (2016). 
28. Y. Chen, H. Wang, B. Dang, Y. Xiong, Q. Yao, C. Wang, Q. Sun, and C. Jin, Sci. Rep. 7, 1 (2017).

29. V. Krishnakumar, R. Ranjith, J. Jayaprakash, S. Boobas, and J. Venkatesan, J. Mater. Sci. Mater. Electron. 28, 13990 (2017).

30. W. Yan, Q. Chen, M. Du, K. M. Yang, X. Cai, X. Meng, and L. Wang, J. Nanosci.

Nanotechnol. 18, 5660 (2018).

31. L. S. Casey and L. D. Wilson, EPPH. 201578 (2015).

32. H. N. Bhatti, Y. Safa, S. M. Yakout, O. H. Shair, M. Iqbal, and A. Nazir, International Int. J. Biol. Macromol. 150, 861 (2020).

33. H. Dai, Y. Huang, and H. Huang, Eco-Friendly Polyvinyl Alcohol/Carboxymethyl Cellulose Hydrogels Reinforced with Graphene Oxide and Bentonite for Enhanced Adsorption of Methylene Blue Elsevier Ltd. (2018)

34. Y. H. Yun, E. S. Kim, W. G. Shim, and S. Do Yoon, J Ind Eng Chem. 68, 57 (2018).

35. D. Zhu, L. Wang, W. Yu, and H. Xie, Sci. Rep. 8, 1 (2018).

36. A. C. Pradhan and T. Uyar, ACS Appl. Mater. Interfaces. 9, 35757 (2017).

37. K. M. Shrestha, C. M. Sorensen, and K. J. Klabunde, J. Phys. Chem. C. 114, 14368 (2010).

38. L. Zhang, Y. C. Zhu, Y. Y. Liang, W. W. Zhao, J. J. Xu, and H. Y. Chen, Anal. Chem. 90, 5439 (2018).

39. K. Saini, R. Manoj Kumar, D. Lahiri, and I. Lahiri, Nanotechnology. 26, 305701 (2015).

40. K. P. Sapkota, I. Lee, M. A. Hanif, M. A. Islam, J. Akter, and J. R. Hahn, Catalysts. 10, (2020).

41. H. R. Kim, T. Ito, B. S. Kim, and I. S. Kim, J. Exp. Nanosci. 8, 852 (2013).

42. S. Paudel, S. Dandeliya, R. Chaurasiya, A. Srivastava, and G. C. Kaphle, J. Magn. Magn. Mater. 406, 8 (2016).

43. L. Muthaiyan, S. Sriram, and D. Balamurugan, Int. J. Nanoelectron. Mater. 11, 33 (2018).

44. K. K. Dey, P. Kumar, R. R. Yadav, A. Dhar, and A. K. Srivastava, RSC Adv. 4, 10123 (2014).

45. M. Aslam, M. A. Kalyar, and Z. A. Raza, Polym. (2020).

46. M. Dong, Q. Lin, D. Chen, X. Fu, M. Wang, Q. Wu, X. Chen, and S. Li, RSC Adv. 3, 11628 (2013).

47. R. Wang, L. Liu, S. Subhan, Y. Muhammad, Y. Hu, M. Huang, Y. Peng, Z. Zhao, and Z. Zhao, Chem. Eng. Technol. 395, 124958 (2020). 
48. S. Dutta, D. Das, A. Dasgupta, and P. K. Das, Chem. Eur. J. 16, 1493 (2010).

49. J. Robinson, K. Xi, R. V. Kumar, A. C. Ferrari, H. Au, M.-M. Titirici, A. Parra Puerto, A. Kucernak, S. D. S. Fitch, and N. Garcia-Araez, J. Phys. Energy. 2, 0 (2020).

50. R. Bibi, L. Wei, Q. Shen, W. Tian, O. Oderinde, N. Li, and J. Zhou, J. Chem. Eng. Data. 62, 1615 (2017).

51. V. K. Gupta, D. Pathania, S. Agarwal, and P. Singh, J. Hazard. Mater. 243, 179 (2012).

52. M. Vakili, M. Rafatullah, B. Salamatinia, A. Z. Abdullah, M. H. Ibrahim, K. B. Tan, Z. Gholami, and P. Amouzgar, Carbohydr. Polym. 113, 115 (2014).

53. S. Wang, X. Li, Y. Liu, C. Zhang, X. Tan, G. Zeng, B. Song, and L. Jiang, J. Hazard. Mater. 342, 177 (2018).

54. S. Karcher, A. Kornmüller, and M. Jekel, Water Sci. Technol. 40, 425 (1999).

55. N. Li, D. Wei, Q. Sun, X. Han, B. Du, and Q. Wei, R. Soc. Open Sci. 5, (2018).

56. V. K. Gupta, S. Agarwal, D. Pathania, N. C. Kothiyal, and G. Sharma, Carbohydr. Polym. 96, 277 (2013).

57. B. Zhu, P. Xia, W. Ho, and J. Yu, Appl. Surf. Sci. 344, 188 (2015).

58. N. Hu, W. Liu, L. Ding, Z. Wu, H. Yin, D. Huang, H. Li, L. Jin, and H. Zheng, J. Nanoparticle Res. 19, (2017).

59. R. S. Hebbar, A. M. Isloor, Inamuddin, M. S. Abdullah, A. F. Ismail, and A. M. Asiri, J Taiwan Inst Chem Eng. 93, 42 (2018).

60. P. R. Tulip and S. J. Clark, Phys. Rev. B Condens. Matter. 74, 15 (2006).

61. T. L. McMEEKIN, M. L. GROVES, and HIPP, N. J. 54 (1964).

62. E. Badetti, L. Calgaro, L. Falchi, A. Bonetto, C. Bettiol, B. Leonetti, E. Ambrosi, E. Zendri, and A. Marcomini, Nanomaterials. 9, (2019).

63. G. Zanatta, C. Gottfried, A. M. Silva, E. W. S. Caetano, F. A. M. Sales, and V. N. Freire, J Chem Phy. 140, (2014).

64. A. M. Silva, B. P. Silva, F. A. M. Sales, V. N. Freire, E. Moreira, U. L. Fulco, E. L. Albuquerque, F. F. Maia, and E. W. S. Caetano, Phys. Rev. B Condens. Matter. 86, 1 (2012).

65. S. Spahr, M. Teixidó, D. L. Sedlak, and R. G. Luthy, Environ. Sci. Water Res. Technol. 6, 15 (2020).

66. T. Gasti, S. Dixit, S. P. Sataraddi, V. D. Hiremani, S. P. Masti, R. B. Chougale, and R. B. Malabadi, J Polym Environ. (2020).

67. G. Sharmila, R. Sakthi Pradeep, K. Sandiya, S. Santhiya, C. Muthukumaran, J. Jeyanthi, N. Manoj Kumar, and M. Thirumarimurugan, J. Mol. Struct. 1165, 288 (2018). 
68. K. Sharma, P. Kumar, G. Verma, and A. Kumar, Optik. 206, 164357 (2020).

69. D. Komaraiah, P. Madhukar, Y. Vijayakumar, M. V. Ramana Reddy, and R. Sayanna, Mater. Today. 3, 3770 (2016).

70. S. Felix, R. B. P. Chakkravarthy, and A. N. Grace, IOP Conference Series: Mater. Sci. Eng. 73, 1 (2015).

71. C. M. Cholant, M. P. Rodrigues, L. L. Peres, R. D. C. Balboni, L. U. Krüger, D. N. Placido, W. H. Flores, A. Gündel, A. Pawlicka, and C. O. Avellaneda J. Solid State Chem. 24, 1867 (2020).

72. P. Yugandhar, T. Vasavi, P. Uma Maheswari Devi, and N. Savithramma, Appl. Nanosci. (Switzerland) 7, 417 (2017).

73. P. S. R. Salunkhe, 5 (2018).

74. K. Guan, Surf. Coat. Technol. 191, 155 (2005).

75. I. Morad, A. M. Alshehri, A. F. Mansour, M. H. Wasfy, and M. M. El-Desoky, Physica B Condens. 597, 412415 (2020).

76. T. S. Soliman and S. A. Vshivkov, J Non Cryst Solids. 519, (2019).

77. T. S. Soliman, S. A. Vshivkov, and S. I. Elkalashy, Opt. Mater. 107, 110037 (2020).

78. M. Aslam, M. A. Kalyar, and Z. A. Raza, J. 47, 3912 (2018).

79. M. M. Rahman Khan, S. Pal, M. M. Hoque, M. R. Alam, M. Younus, and H. Kobayashi, ACS Omega. 4, 6144 (2019).

80. M. B. Gawande, A. Goswami, F. X. Felpin, T. Asefa, X. Huang, R. Silva, X. Zou, R. Zboril, and R. S. Varma, Chem. Rev. 116, 3722 (2016).

81. V. K. Mrunal, A. K. Vishnu, N. Momin, and J. Manjanna, Environ. Nanotechnol. Monit. Manag. 12, 100265 (2019). 
Figures

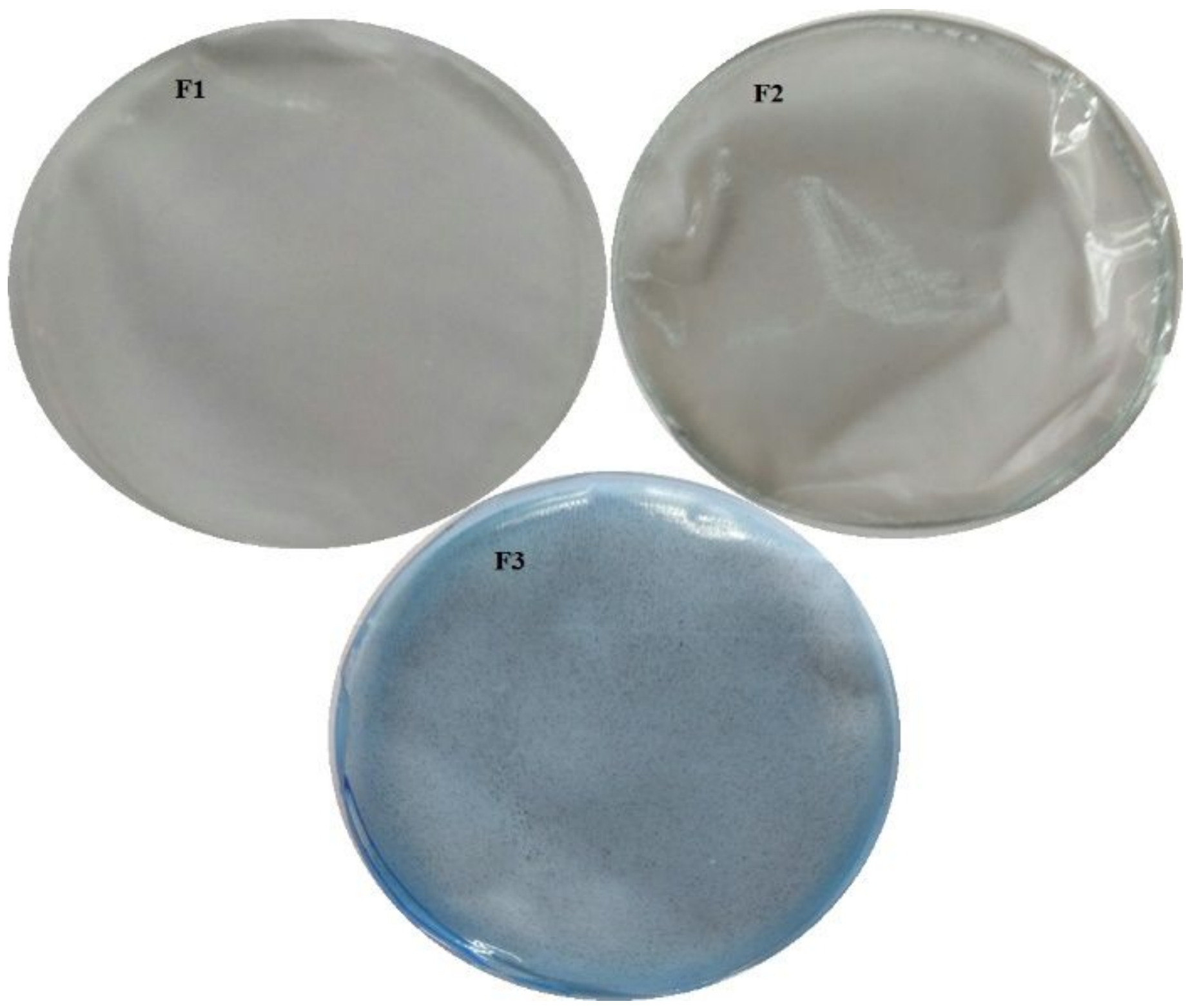

Figure 1

Image of prepared PVA and its composite films 


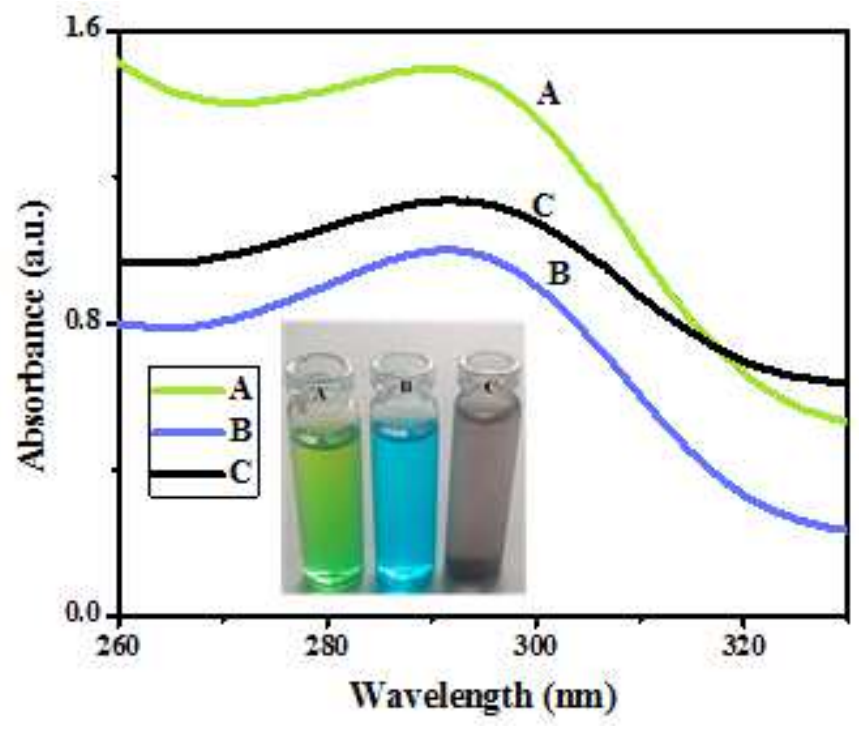

Figure 2

UV-Vis spectra of: A) plant extract, B) Cu (NO3)2.3H2O and C) CuO NTs

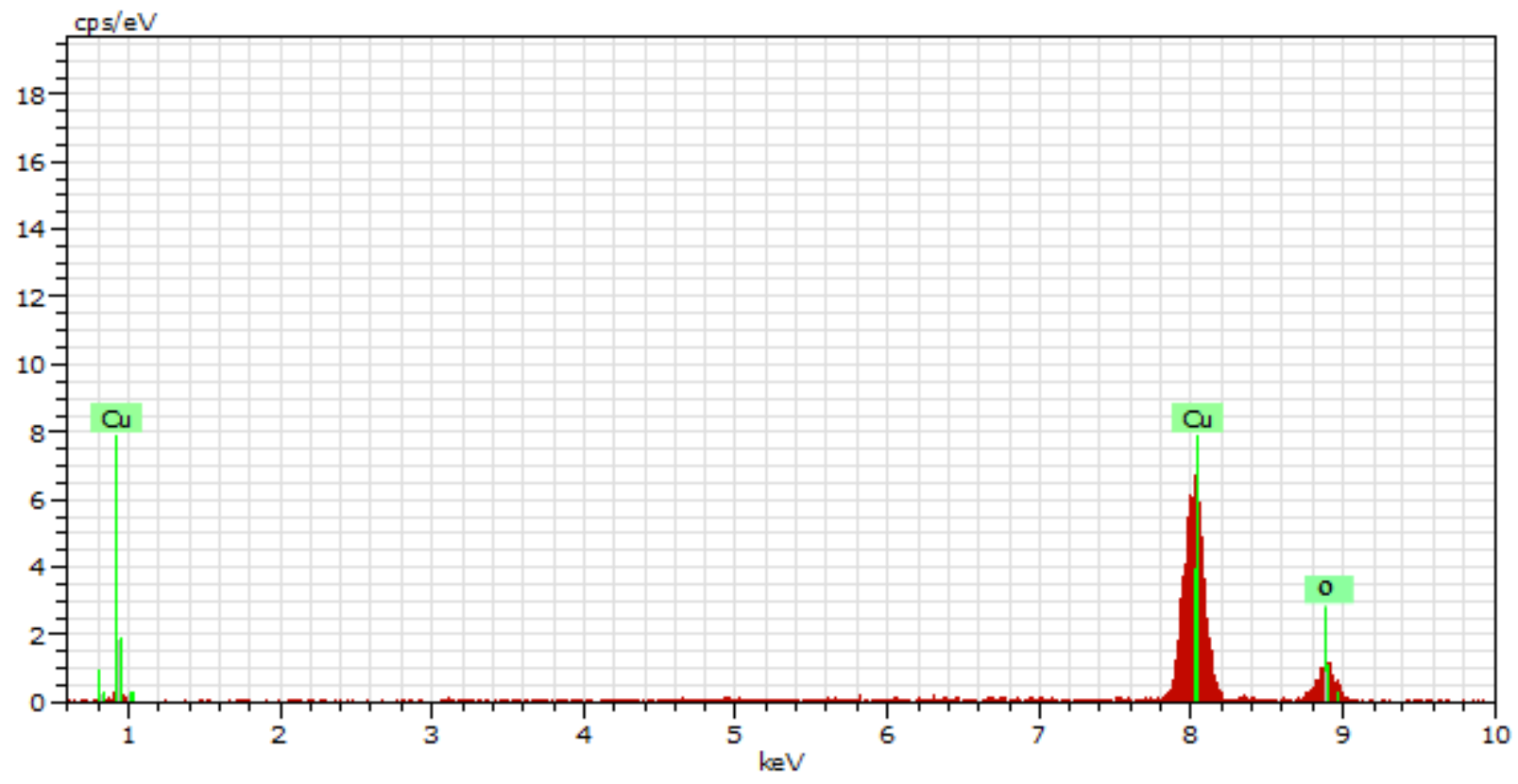

Figure 3

EDX spectrum of CuO NTs 


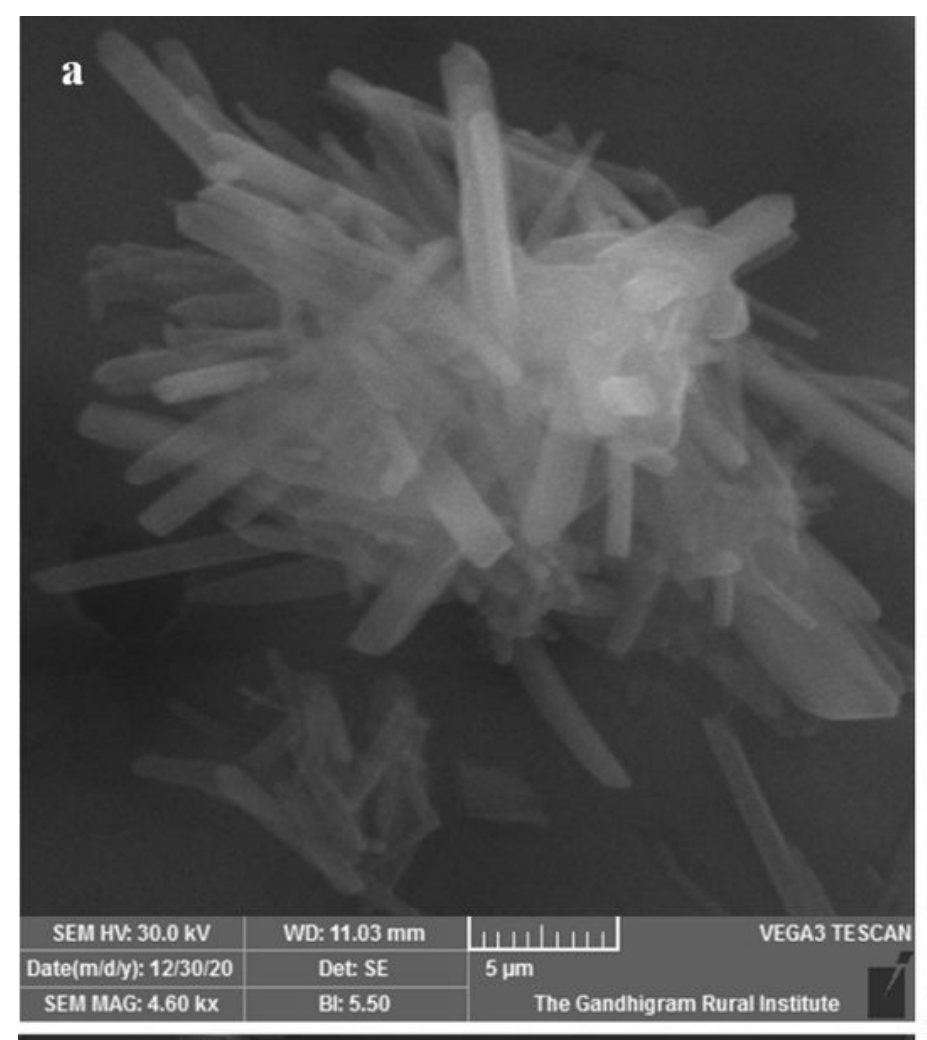

b

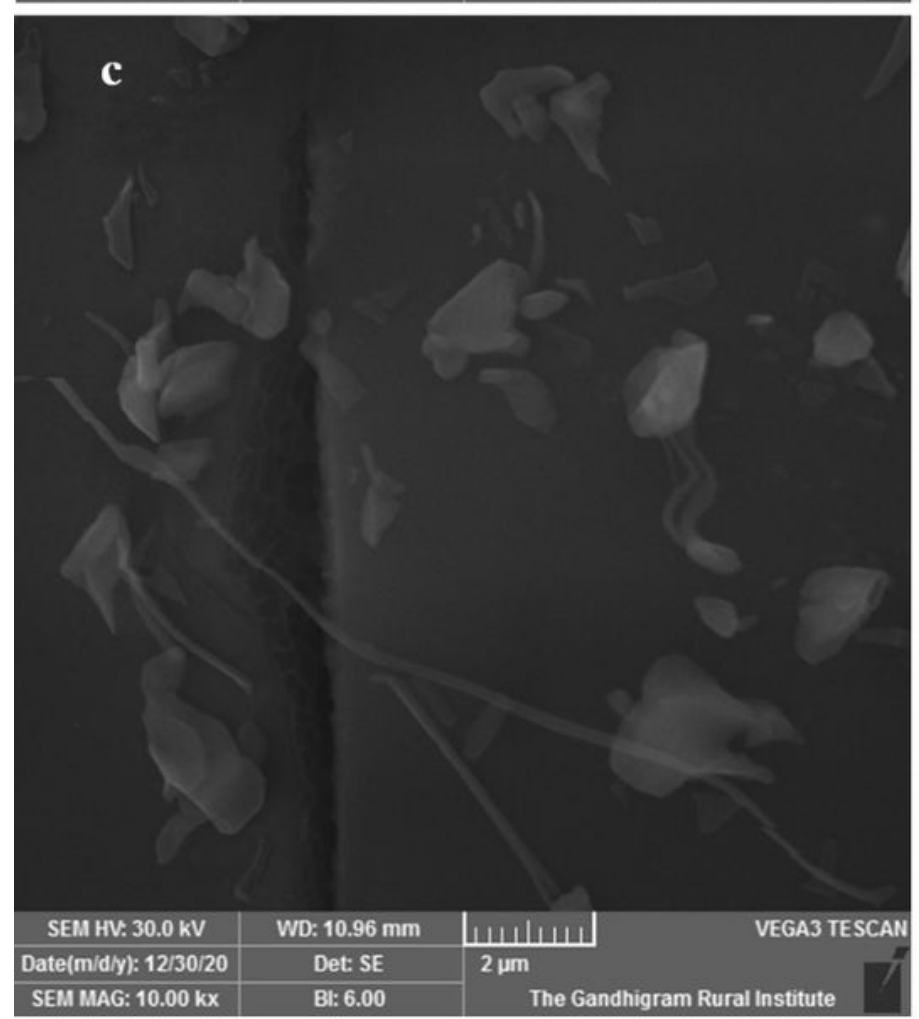

\begin{tabular}{|c|c|c|c|}
\hline SEM HV: $30.0 \mathrm{kV}$ & WD: $10.90 \mathrm{~mm}$ & 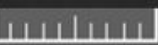 & VEGA3 TESCAN \\
\hline ate $(m / d / y): 12 / 30 / 20$ & Det: SE & $50 \mu \mathrm{m}$ & \\
\hline SEM MAG: $496 \mathrm{x}$ & Bl: 5.50 & The Gandl & al Institute \\
\hline
\end{tabular}

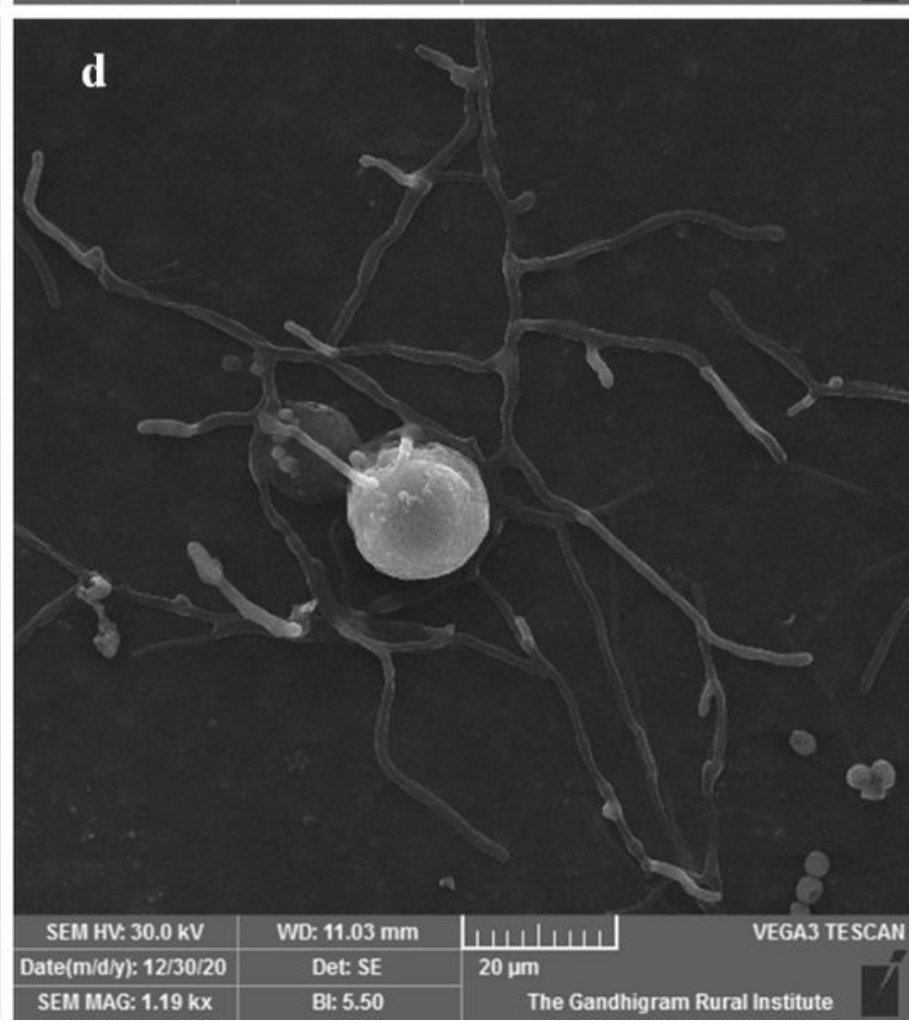

Figure 4

SEM images, a) CuO NTs, b) F1, F2 and F3 


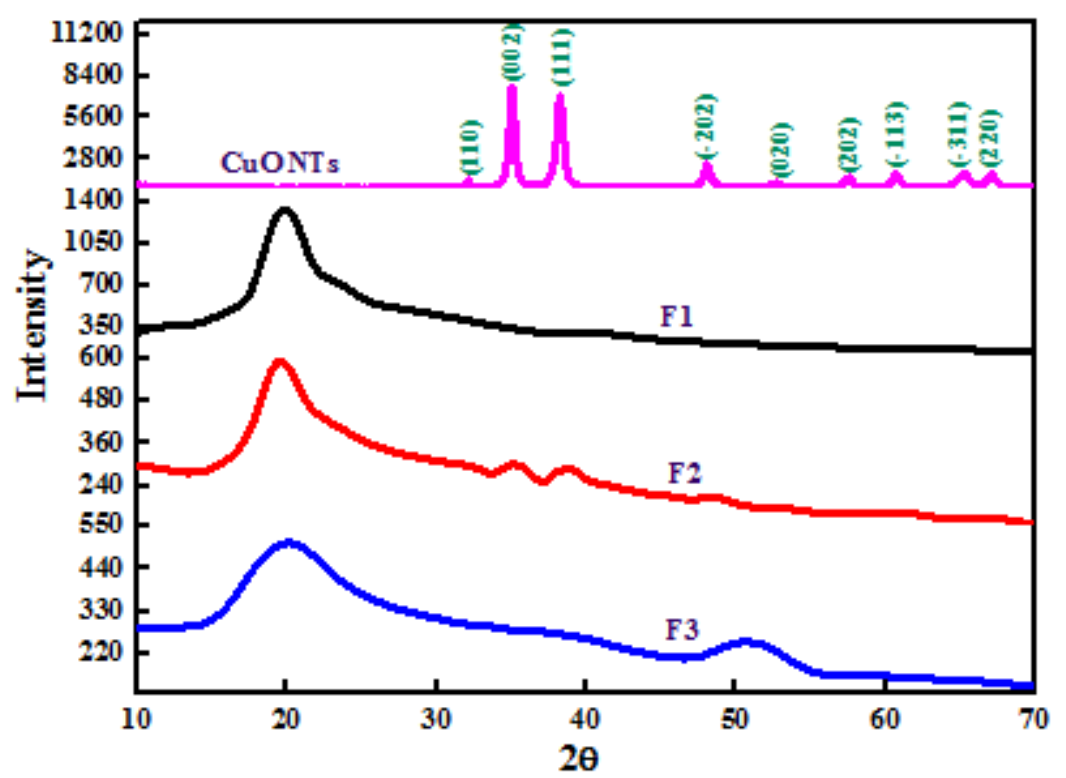

Figure 5

XRD pattern of CuO NTs, F1, F2 and F3 films
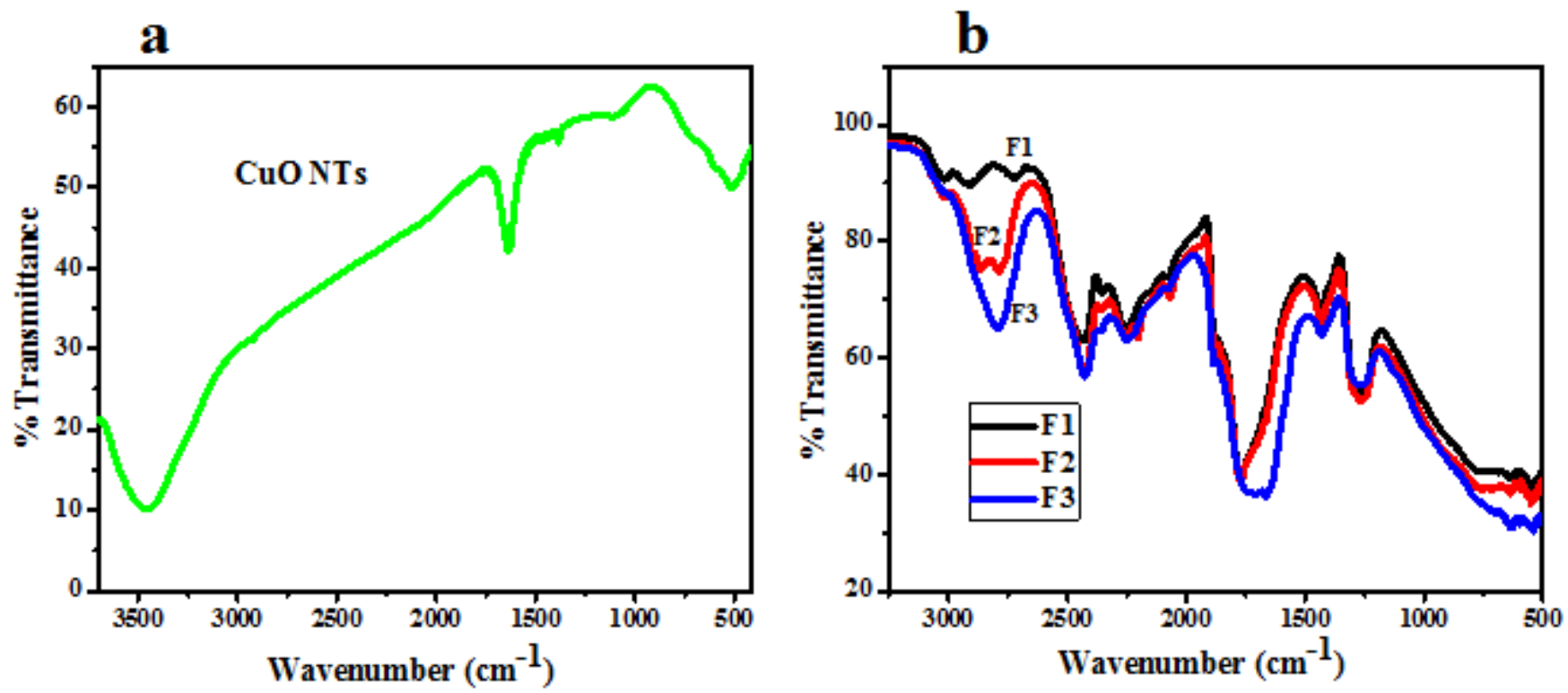

Figure 6

a) FT-IR spectrum of CuO NTs and b) ATR-FT-IR of F1-F3 films 


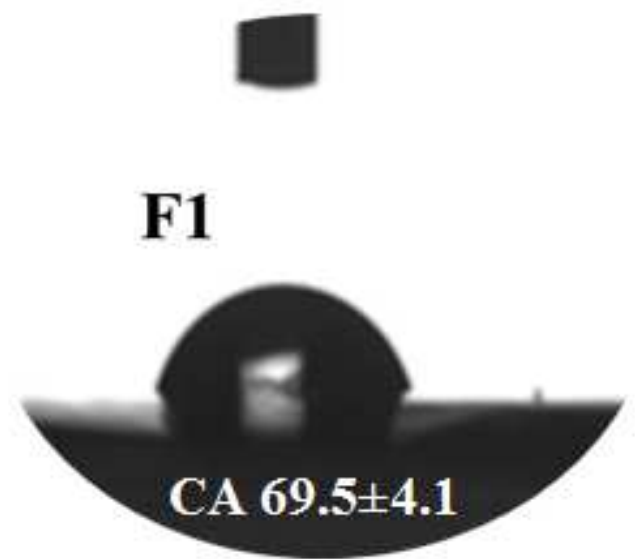

\section{F2}

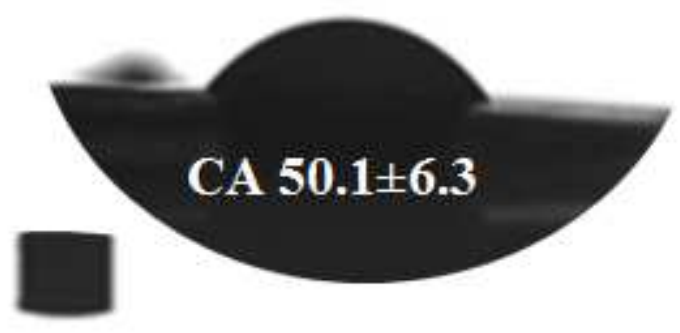

\section{F3}

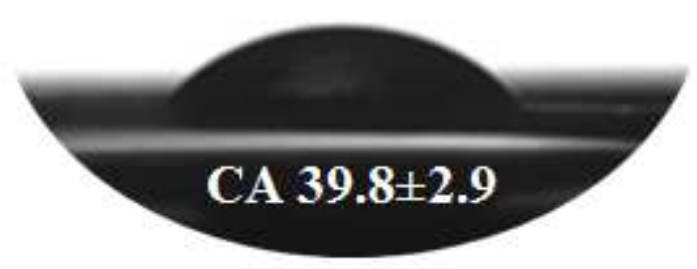

Figure 7

Water Contact Angle of films; F1= 69.5 $\pm 4.1, F 2=50.3 \pm 16.3$ and F3= 39.8 \pm 2.9
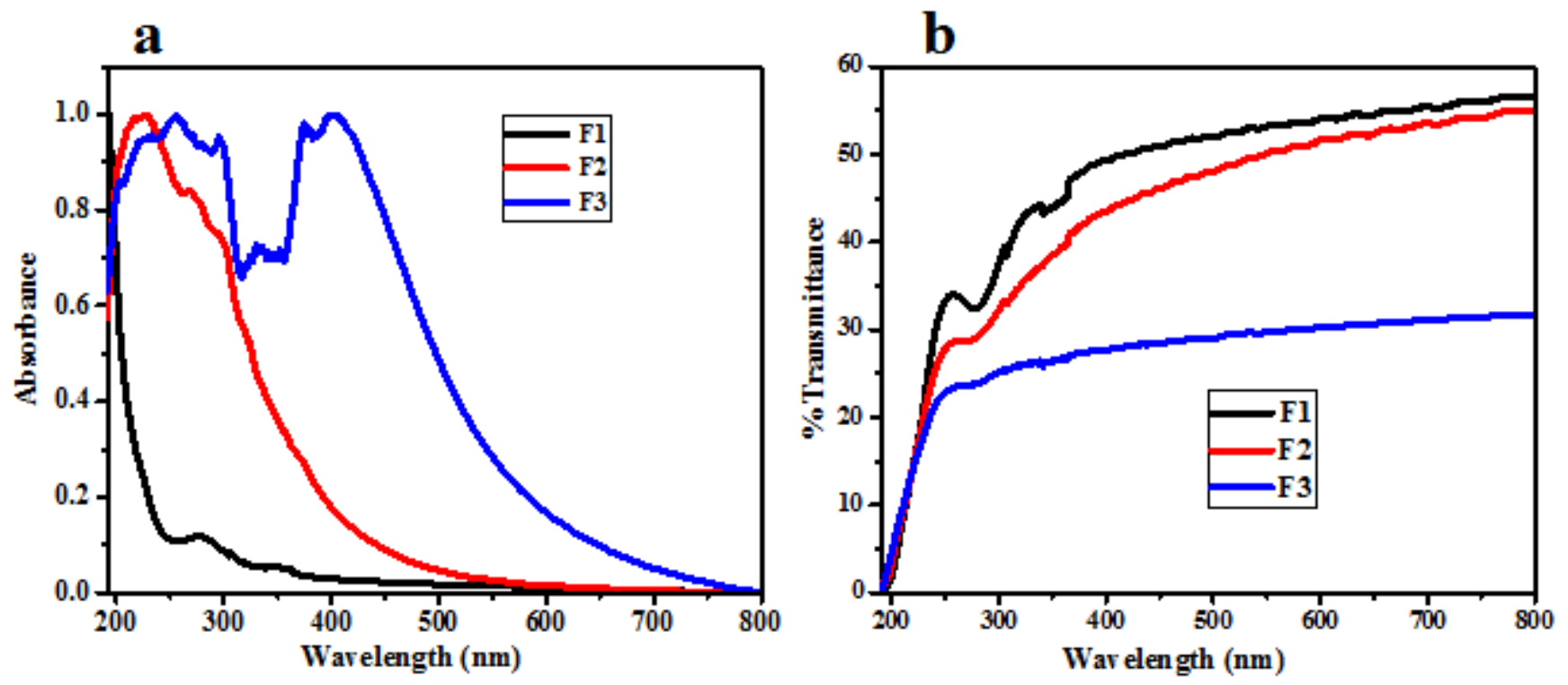

Figure 8

a) UV-Vis absorption spectra for PVA nanocomposite films F1-F3. 8b) Transmittance spectra v/s Wavelength for PVA nanocomposite films F1-F3. 

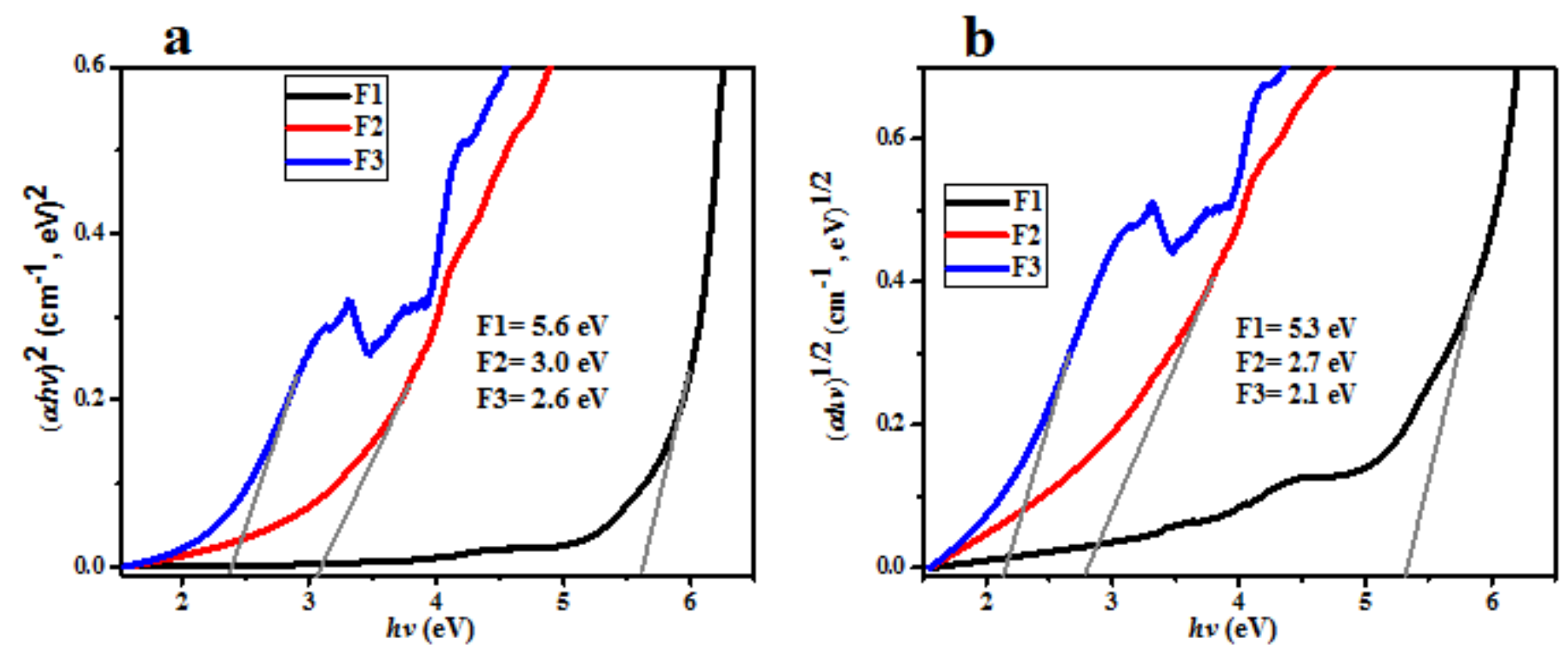

Figure 9

The plots of (a) direct [(ahu) 2 vs. (hu)] and (b) indirect [(ahu) $1 / 2$ vs. (hu)] optical band gaps polymer nanocomposite films F1-F3
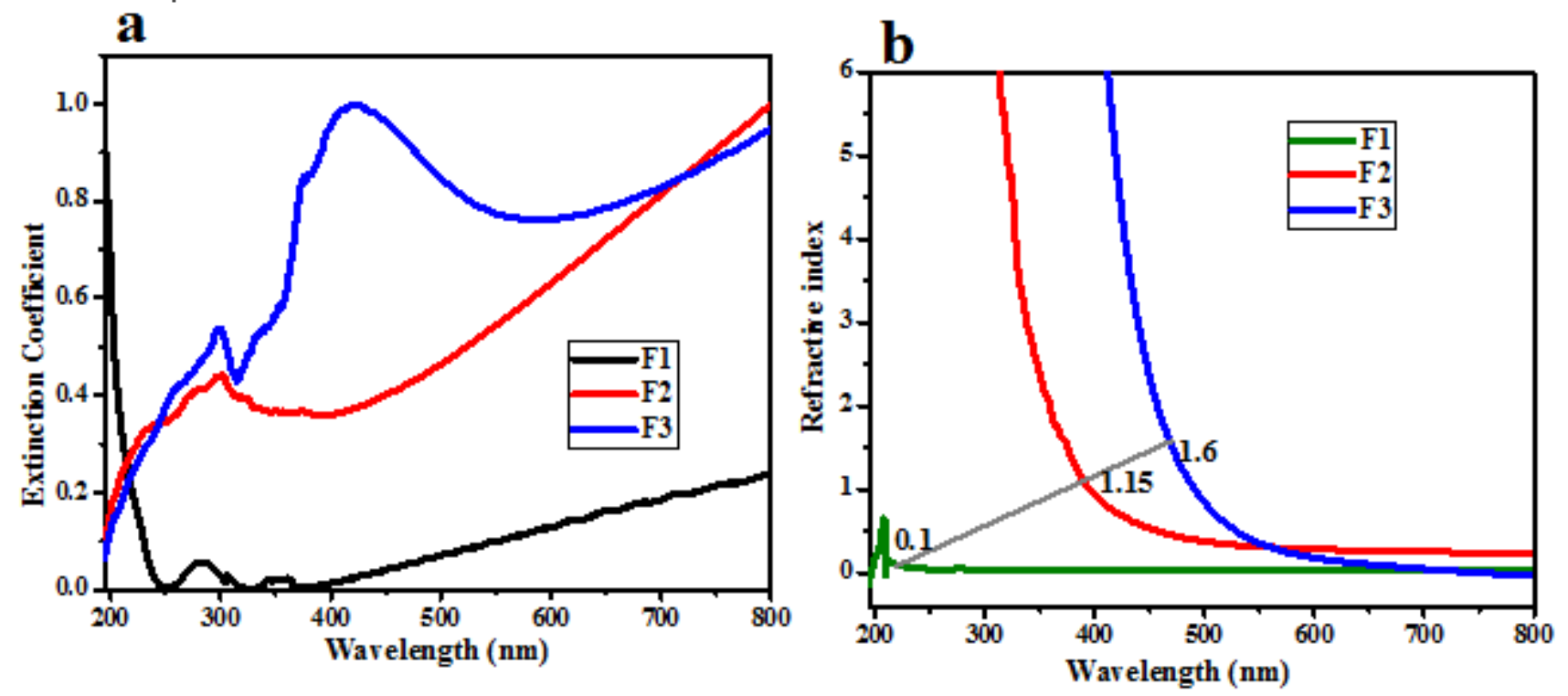

Figure 10

a) Extinction coefficient vs. the wavelength of the PVA nanocomposite films F1-F3. b) Refractive index vs. the wavelength of the PVA nanocomposite films F1-F3. 


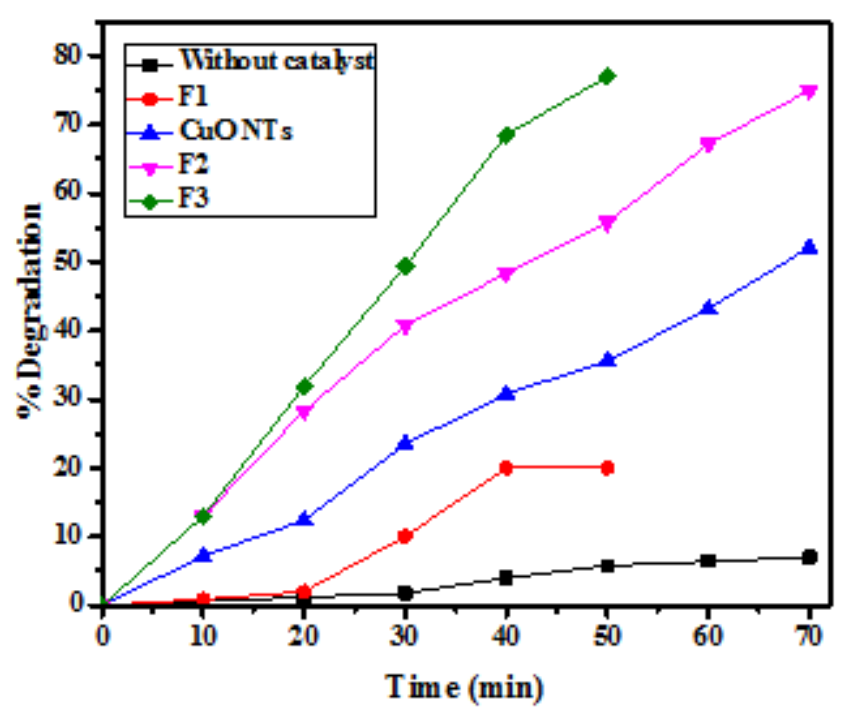

Figure 11

Percentage degradation of MB; catalyst free, and in the presence of CuO NTs, F1, F2 and F3 

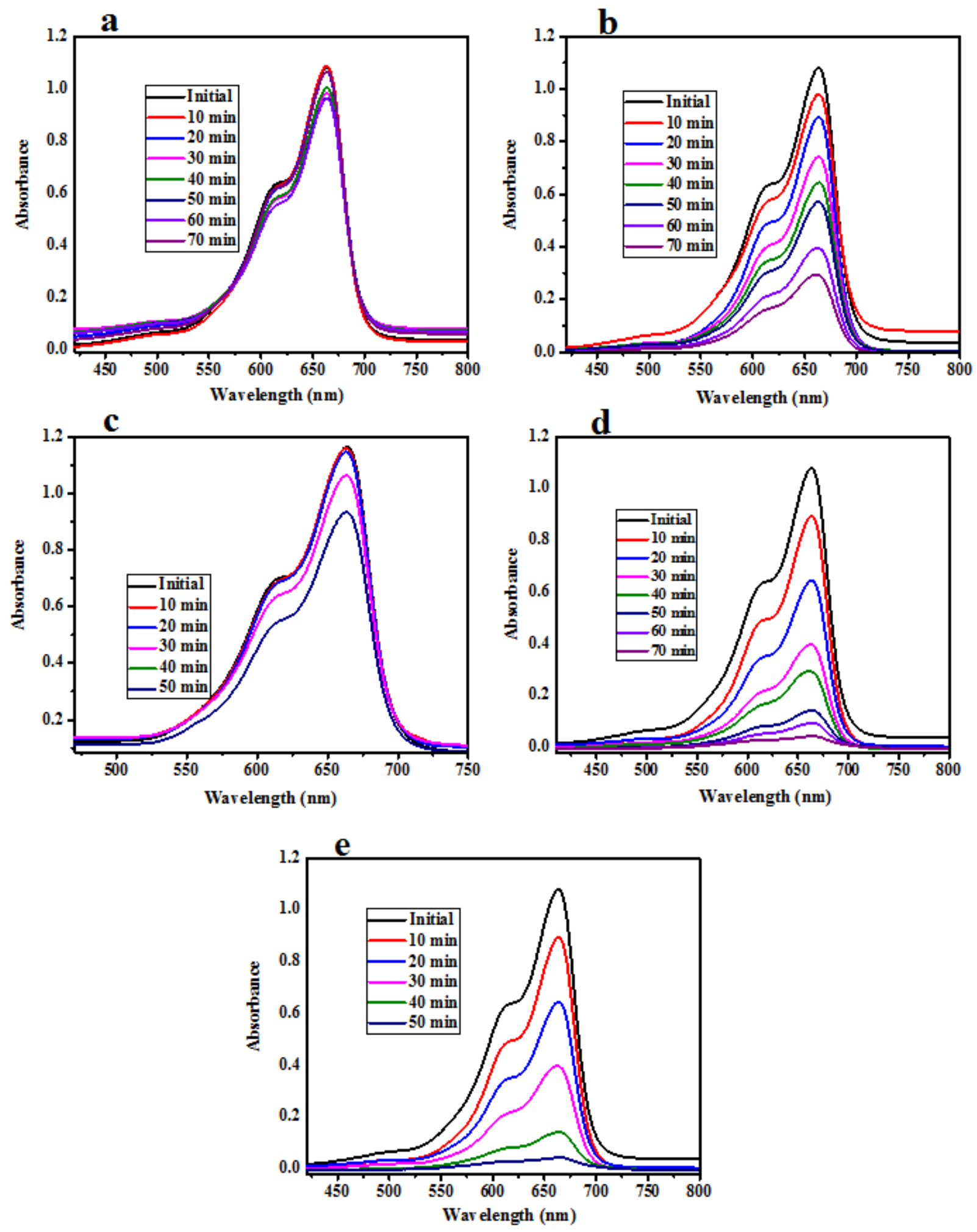

Figure 12

Changes in the UV-Vis absorption spectra of MB aqueous solution in the presence of (a) Without catalyst, (b) CuO NTs, (c) PVA, (d) PVA-CuO NTs, and (e) PVA-CuO NTs-Asp composite films. 

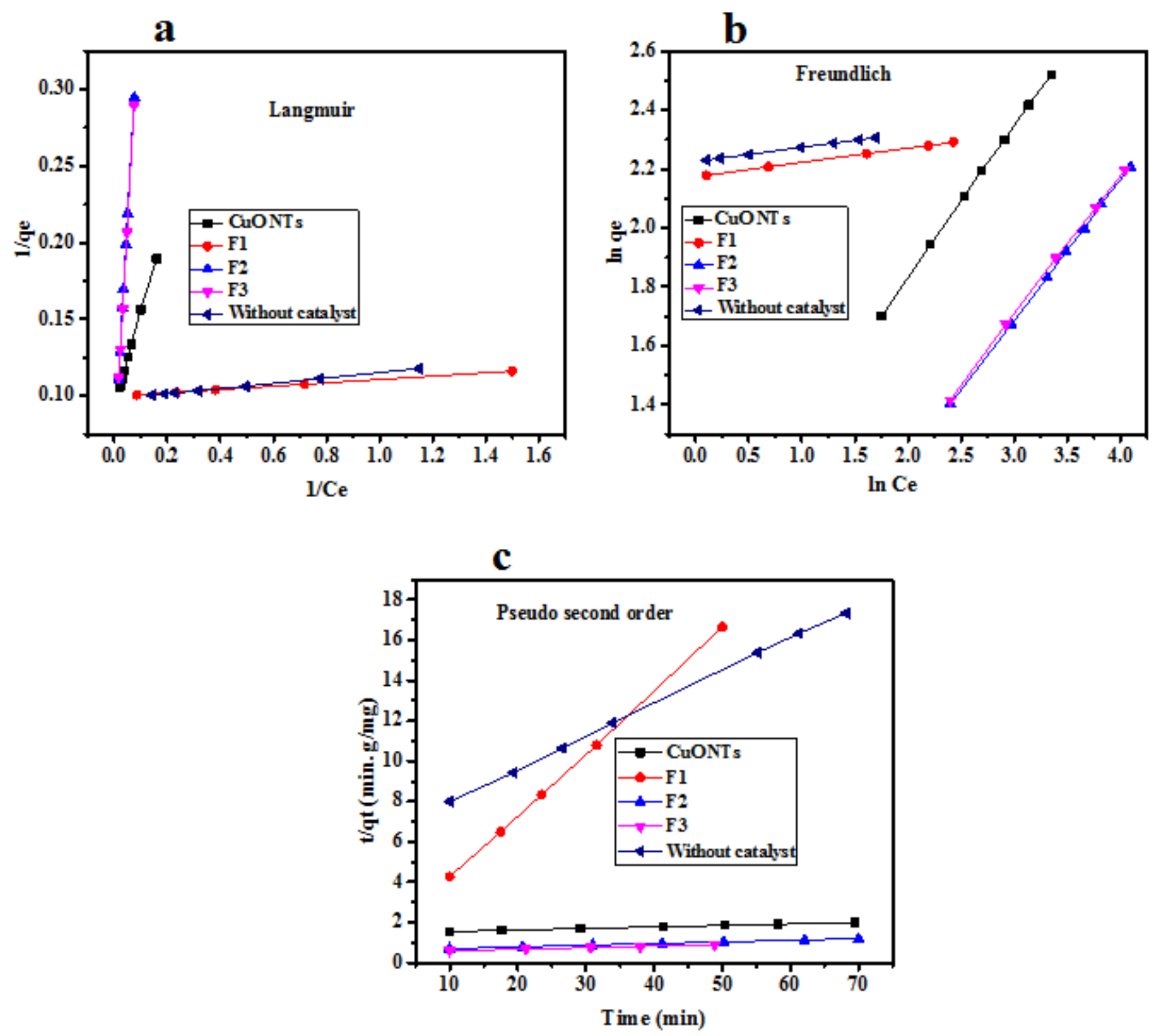

Figure 13

a) Langmuir model, b) Freundlich model and c) Pseudo second order model for the different photocatalysts 

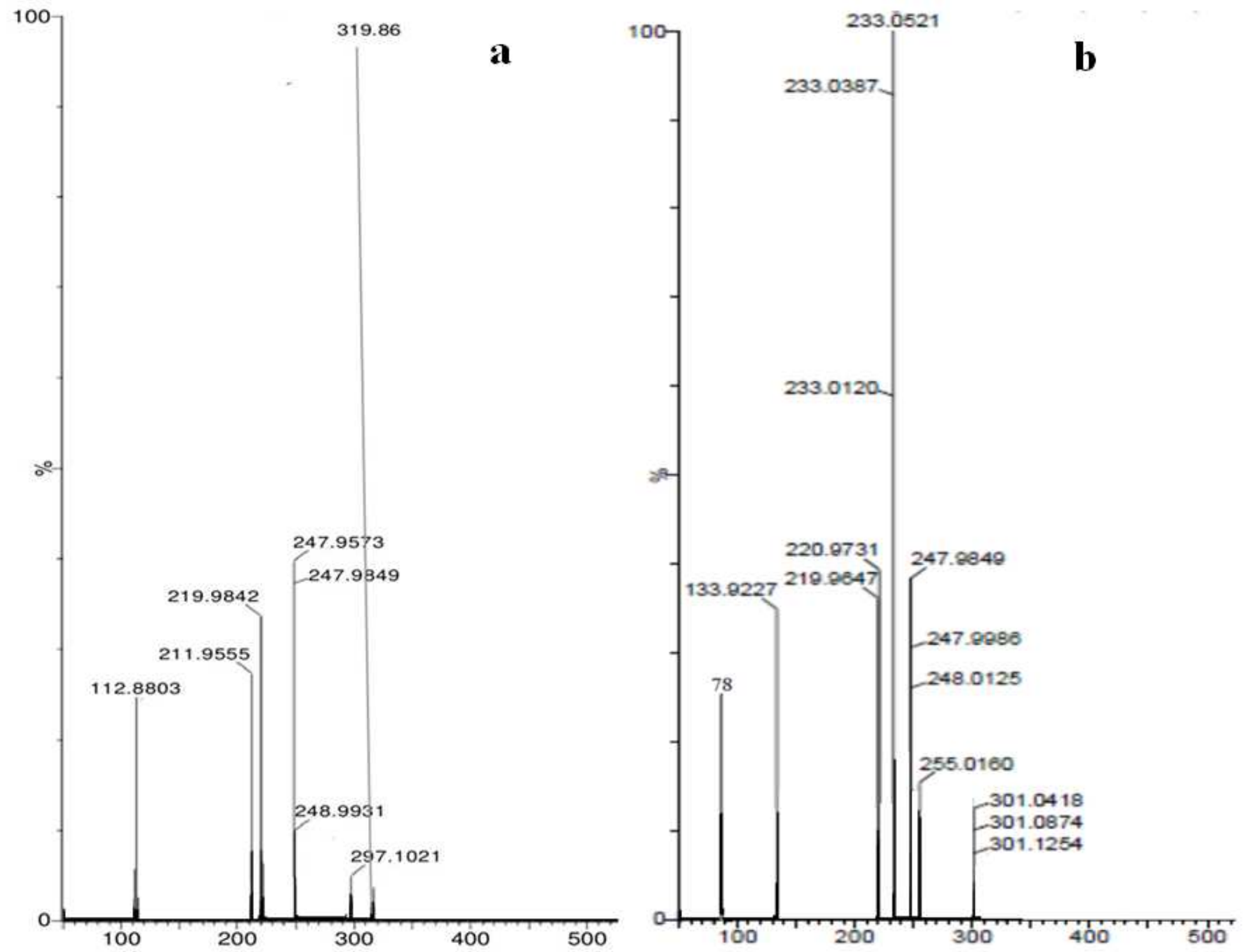

Figure 15

LC-MS product of: a) before degradation of the dye MB and b) after degradation of dye MB.

\section{Supplementary Files}

This is a list of supplementary files associated with this preprint. Click to download.

- supportinginformation.docx 